INEEL/EXT-99-01378

January 2000

\title{
Thermal Conversion of Methane to Acetylene Final Report
}

\author{
J. R. Fincke \\ R. P. Anderson \\ T. Hyde \\ R. Wright \\ R. Bewley \\ D. C. Haggard \\ W. D. Swank
}




\title{
Thermal Conversion of Methane to Acetylene Final Report
}

\author{
J. R. Fincke \\ R. P. Anderson \\ T. Hyde \\ R. Wright \\ R. Bewley \\ D. C. Haggard \\ W. D. Swank
}

Published January 2000

Idaho National Engineering and Environmental Laboratory Idaho Falls, Idaho 83415

\author{
Prepared for the \\ U.S. Department of Energy \\ Under DOE Idaho Operations Office \\ Contract DE-AC07-99ID13727
}




\begin{abstract}
This report describes the experimental demonstration of a process for the direct thermal conversion of methane to acetylene. The process utilizes a thermal plasma heat source to dissociate methane. The dissociation products react to form a mixture of acetylene and hydrogen. The use of a supersonic expansion of the hot gas is investigated as a method of rapidly cooling (quenching) the product stream to prevent further reaction or thermal decomposition of the acetylene which can lower the overall efficiency of the process.
\end{abstract}




\section{ACKNOWLEDGEMENT}

The authors wish to acknowledge financial assistance from the U.S. Department of Energy's National Energy Technical Laboratory (NETL).

The project was funded under the Emerging Processing Technology Applications - Gas to Liquids Product Line. Programmatic support from Dr. Venkat Venkataraman and Dr. Daniel Driscoll of the NETL is also gratefully acknowledged. 


\section{DISCLAIMER}

This report was prepared as an account of work sponsored by an agency of the United States Government. Neither the United States Government nor any agency thereof, nor any of their employees, makes any warranty, expressed or implied, or assumes any legal liability or responsibility for the accuracy, completeness, or usefulness of any information, apparatus, product, or process disclosed, or represents that its use would not infringe privately owned rights. Reference herein to any specific commercial product, process, or service by trade name, trademark, manufacturer, or otherwise does not necessarily constitute or imply its endorsement, recommendation, or favoring by the United States Government or any agency thereof. The views and opinions of authors expressed herein do not necessarily state or reflect those of the United States Government. 


\section{CONTENTS}

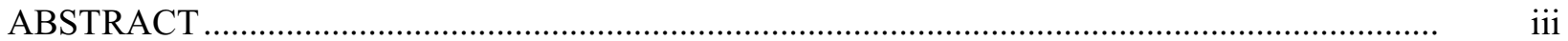

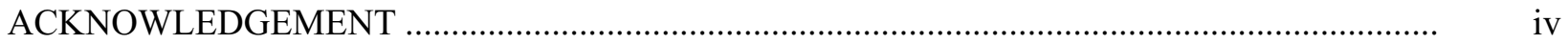

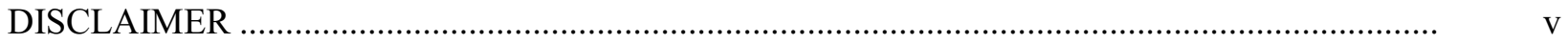

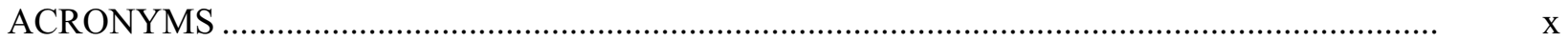

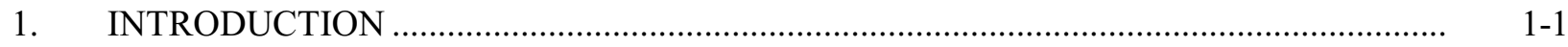

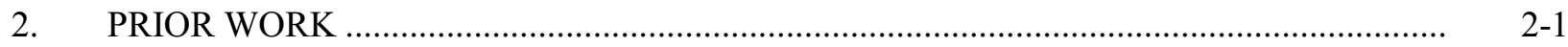

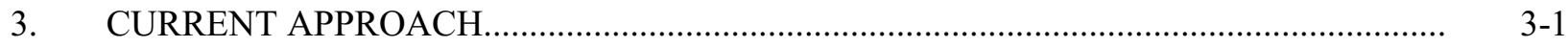

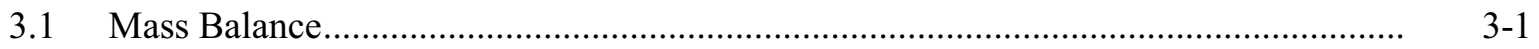

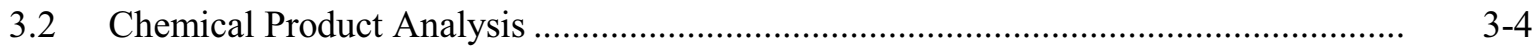

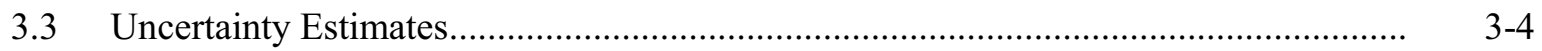

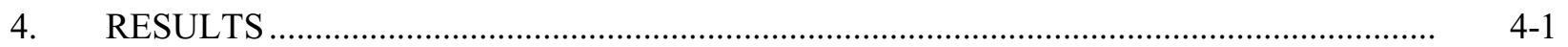

4.1 Results with Converging-Diverging Nozzle..........................................................

4.2 Results Without Converging-Diverging Nozzle.......................................................

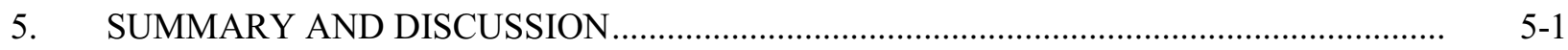

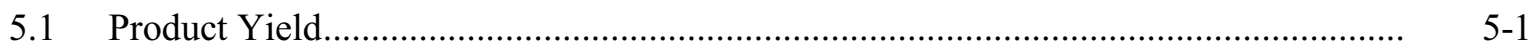

5.2 Specific Energy Consumption.......................................................................

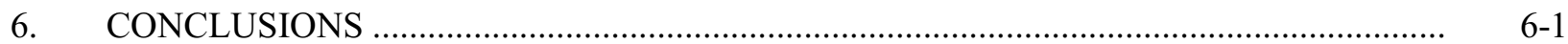

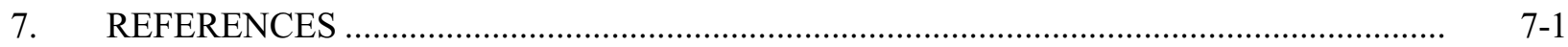

Appendix A-Evaluation of Commercially Available Plasma Systems for the Conversion of Methane to Acetylene

Appendix B-Representative Data Tables

\section{FIGURES}

1-1. Schematic of Huels plasma arc process for acetylene production ........................................ $1-2$

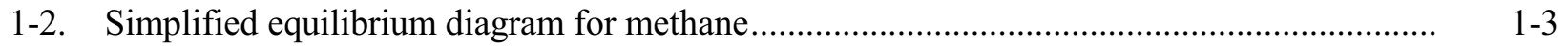

1-3. Simplified equilibrium diagram for methane where the solid phase of carbon is not included as a species 
3-1. Process and Instrumentation Diagram …............................................................... $3-2$

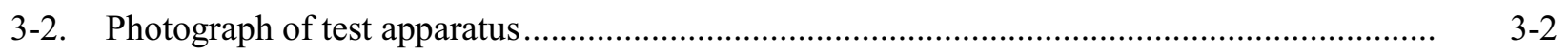

3-3. Schematic of torch, injector, reactor and nozzle assembly, flow is right to left .................... $3-3$

3-4. Photograph of torch, injector, reactor and nozzle assembly, flow is right to left ................. $3-3$

3-5. Cold flow overall mass balance validation ...................................................................

3-6. Cold flow overall mass balance error in percent of reading ...........................................

4-1. Partitioning of energy loss to cooling water ..............................................................

4-2. The theoretical maximum amount of methane that can be processed in current system,

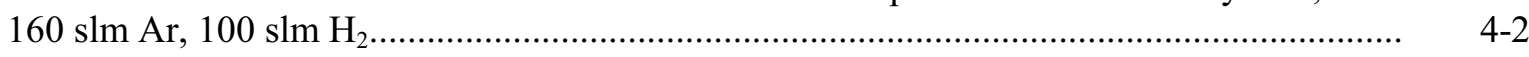

4-3. Conversion efficiency as a function of methane feed rate, plasma power is constant at $60 \mathrm{~kW}$, and plasma gas flow rates are constant at $160 \mathrm{slm} \mathrm{Ar}$ and $100 \mathrm{slm} \mathrm{H}_{2} \ldots$

4-4. Estimated reactor temperature and reactor residence time as a function of methane injection rate

4-5. Methane conversion efficiency as a function of reactor pressure

4-6. Acetylene yield as a function of methane injection rate

4-7. Normalized acetylene yield

4-8. Yield of all other observed hydrocarbons

4-9. Yield of all other observed hydrocarbons less methane

4-10. Conversion efficiency as a function of methane feed rate, plasma power is constant at $60 \mathrm{~kW}$ and plasma gas flow rates are constant at $160 \mathrm{slm} \mathrm{Ar}$ and $100 \mathrm{slm} \mathrm{H}_{2}$

4-11. Acetylene yield as a funciton of methane injection rate

4-12. Normalized acetylene yield

4-13. Yield of all other observed hydrocarbons, less methane

4-14. Acetylene yield as a function of pressure, converging-diverging nozzle removed, $160 \mathrm{slm} \mathrm{Ar}, 100 \mathrm{slm} \mathrm{H}_{2}, 98.5 \mathrm{slm} \mathrm{CH}_{4}$

4-15. Hydrocarbon yield as a function of reactor pressure

5-1. Specific energy consumption 


\section{TABLES}

2-1. Summary of prior results on the plasma conversion of natural gas to acetylene .................... $2-2$

2-2. Comparison of Huels and DuPont processes .................................................................. 2-3

3-1. Summary of estimated uncertainties in primary measurements ......................................... $3-6$

3-2. Species concentrations measured, molecular weights, and number of carbon and hydrogen atoms

3-3. Estimated uncertainties in derived quantities ................................................................. $3-11$

3-4. Rate of production of yield of solid carbon soot............................................................... $3-12$

3-5. Example of mass balance performance, $140 \mathrm{slm} \mathrm{Ar}, 100 \mathrm{slm} \mathrm{H}_{2}, 120.8 \mathrm{slm} \mathrm{CH}_{4} \ldots \ldots \ldots \ldots \ldots \ldots . . . . .12$

4-1. Gas chromatograph analysis of natural gas reactant and product stream in mole percent, $60 \mathrm{~kW}$ plasma power, $140 \mathrm{slm} \mathrm{Ar}, 100 \mathrm{slm} \mathrm{H}_{2}$, and $98.5 \mathrm{slm}$ natural gas.............................

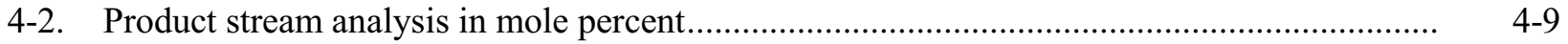




\section{ACRONYMS}

CE conversion efficiency

NETL National Energy Technical Laboratory

P\&ID Process and Instrumentation Diagram

PAHs polycyclic aromatic hydrocarbons

RGA residual gas analyzer

SER specific energy requirement

slm standard liters per minute 


\section{Thermal Conversion of Methane to Acetylene Final Report}

\section{INTRODUCTION}

Large quantities of natural gas exist in various remote parts of the world where no pipeline facilities exist and it cannot be economically transported to end use markets for conventional use. During the last ten years or so, there has been renewed interest in utilization of remotely located natural gas. The motivation to augment declining oil production is often economic, or can be due to changing regulatory or political climate. A solution to this dilemma is on site conversion of methane to more easily transported relatively high value products. These products may be liquid fuels or high-value feedstocks for the chemical industry. A number of possible approaches exist, e.g. conversion to liquids via the syngas and Fischer-Tropsch approach. An example of an alternative approach is direct pyrolysis of methane to acetylene. This is followed by polymerization to benzene, styrene, and higher aromatics (Fields, et al., 1986, Winzenburg and DeMarco, 1991; Timmons, He, and Jang, 1992) or if water is present, a wide range of aliphatics is also formed. This program addresses the demonstration of a thermal process for the conversion of natural gas to acetylene.

Chemische Werke Huels has been using an electric arc process to produce acetylene since the 1940s (Gladish, 1962). The original Huels plant used the low-boiling components of the motor fuel industry as raw material; however, a wide range of hydrocarbons including natural gas was shown to be suitable as process feed stocks. The Huels reactor is shown schematically in Figure 1-1. Methane and/or hydrogen comprise the plasma gas. Heavier hydrocarbons were injected downstream of the discharge. The residence time in the discharge and reactor section is on the order of milliseconds (ms). Immediately downstream of the reactor section the gas is abruptly cooled by liquid water spray injection. The dissociation of all hydrocarbons into carbon and hydrogen begins at relatively low temperatures. For example the dissociation of methane begins at around $500{ }^{\circ} \mathrm{C}$ and is complete by $1000{ }^{\circ} \mathrm{C}$. If the process is strictly in equilibrium, the thermodynamically preferred products between about 1000 and $2500{ }^{\circ} \mathrm{C}$ are solid carbon and molecular hydrogen (Outokumpu Research, 1994), Figure 1-2. As the temperature increases, hydrogen dissociates $\left(\mathrm{T}>2500{ }^{\circ} \mathrm{C}\right)$, acetylene forms, and reaches a maximum concentration at $\mathrm{T} \cong 3000^{\circ} \mathrm{C}$. Conversion to acetylene competes with the formation of the $\mathrm{C}_{2} \mathrm{H}$ radical. Gaseous atomic and diatomic carbon appear above $3800{ }^{\circ} \mathrm{C}$. The equilibrium formation of acetylene is characterized by the requirement of very high temperatures, around $3000{ }^{\circ} \mathrm{C}$. Assuming that upon cooling the $\mathrm{C}_{2} \mathrm{H}$ radical combines with either atomic or molecular hydrogen to produce acetylene, the maximum theoretical yield, defined as the amount of carbon contained in the acetylene formed divided by the amount of carbon in the methane feedstock, is approximately $91 \%$. Because the formation of acetylene from methane is strongly endothermic, relatively large amounts of energy are required per unit mass of acetylene formed. When acetylene is made from paraffins the energy of formation per gram atom of carbon decreases with increasing chain length; for olefins, the energy of formation increases (Gladish 1962).

In practice, however, the rate of formation of unsaturated hydrocarbons - acetylene and ethyleneis much faster than the complete decomposition reaction and the subsequent formation of solid carbon soot. In fact, it is known that the formation of polycyclic aromatic hydrocarbons (PAHs) is a major nucleation mechanism for soot (Frenklach and Wang 1994). Benzene rings and higher aromatics are thought to be formed from acetylene. The PAHs increase in molecular weight by acetylene addition and become hydrogen deficient by hydrogen abstraction leading to the formation of primary soot particles. These primary soot particles continue to grow via the decomposition of acetylene on their surfaces. Hence the formation of acetylene precedes decomposition into soot and hydrogen. If the product stream is subsequently rapidly cooled or quenched to temperatures where the products are stable before soot has 


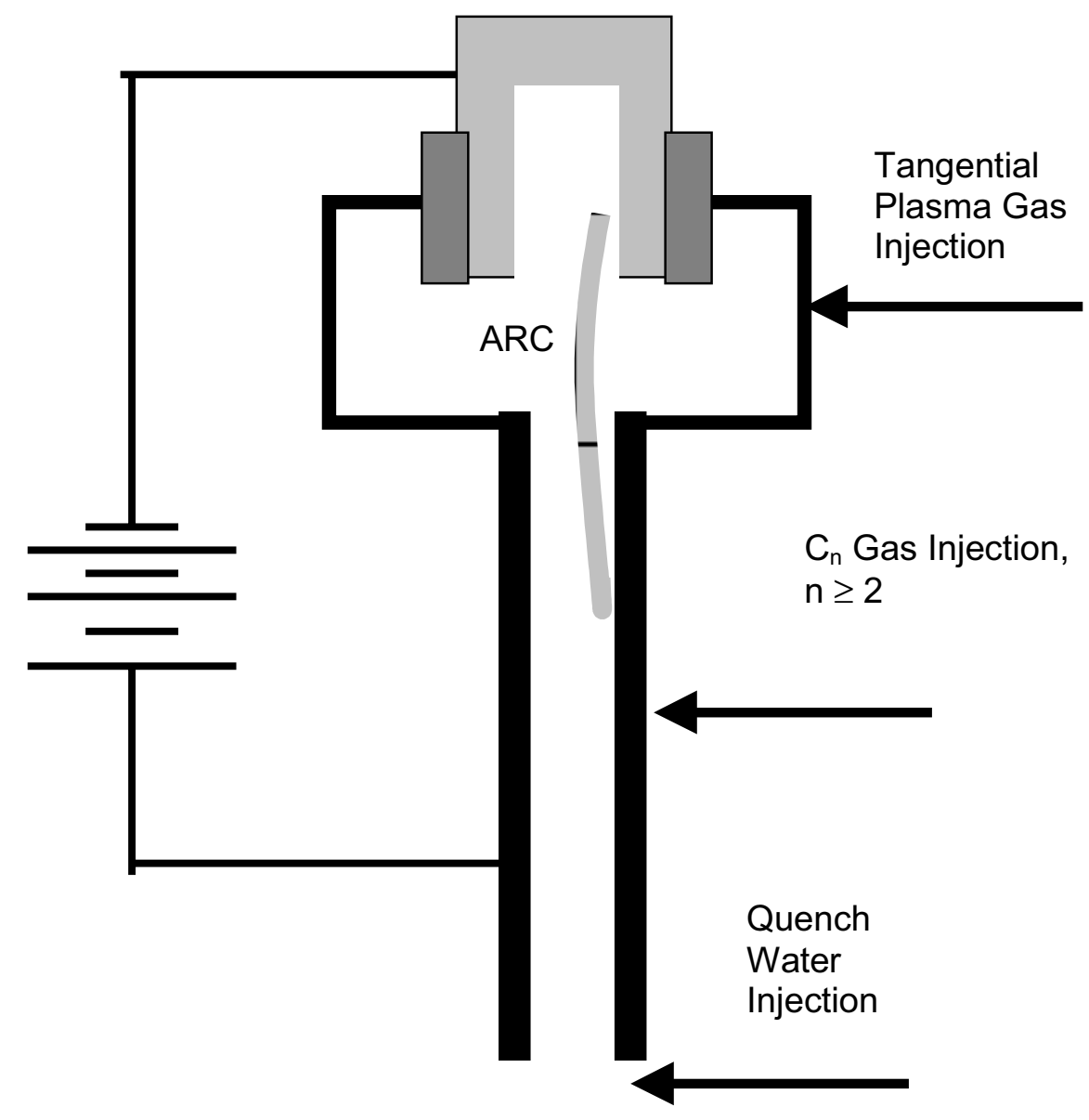

Figure 1-1. Schematic of Huels plasma arc process for acetylene production.

time to nucleate and grow, the desired composition is frozen in. A second, modified equilibrium composition diagram (Outokumpu Research, 1994) for the $\mathrm{CH}_{4}$ system is shown in Figure 1-3. In this calculation the solid phase of carbon is not considered as a possible product. The result is the formation of acetylene with a maximum theoretical yield of $98.5 \%$ at a temperature of around $1875{ }^{\circ} \mathrm{C}$. The Huels process operates in this lower temperature regime.

Even at the reduced temperature of $1875^{\circ} \mathrm{C}$ vs. $3000^{\circ} \mathrm{C}$, the process cannot readily be realized by heat transmission through vessel walls because of materials limitations. In addition, to avoid the formation of solid carbon soot, heating should be as rapid as possible followed immediately by a rapid quench. Arc heating accomplishes the rapid heating, and a water spray quench is used in the Huels process to rapidly cool the product stream. The quench rates obtained in the Huels process are reportedly $700{ }^{\circ} \mathrm{C}$ in approximately one millisecond for a maximum cooling rate of $0.7 \times 10^{6}{ }^{\circ} \mathrm{C} / \mathrm{s}$. The reactors used in the Huels process are relatively large, on the order of $100 \mathrm{~mm}$ in diameter, $1.5 \mathrm{~m}$ in length and operate at power levels as high as $8 \mathrm{MW}$. In the work reported here we will regard the Huels process, as reported in Gladish (1962), as the benchmark to be compared against. In general these comparisons will be made quantitative through the calculation of various yield, conversion efficiency (CE), and energy consumption metrics defined below. Except as noted, only feedstocks containing predominately methane (natural gas) will be considered. 


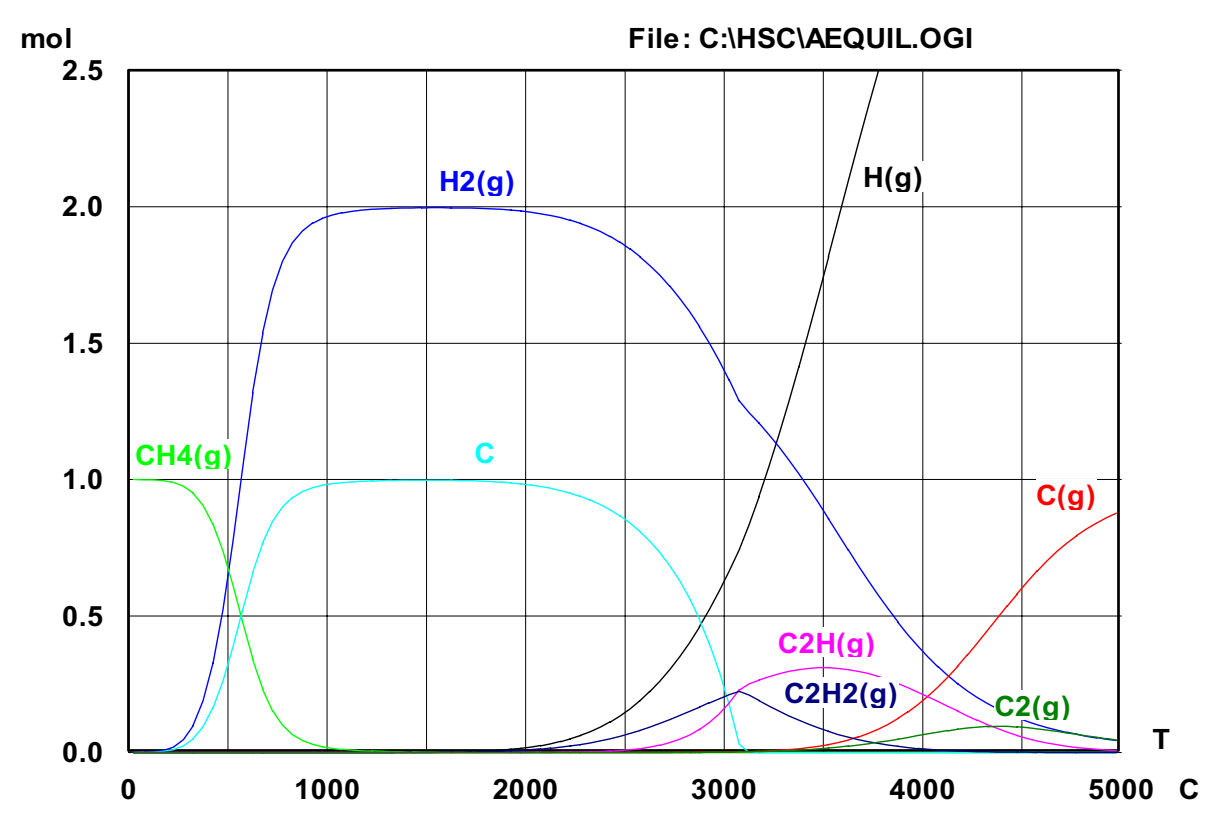

Figure 1-2. Simplified equilibrium diagram for methane.

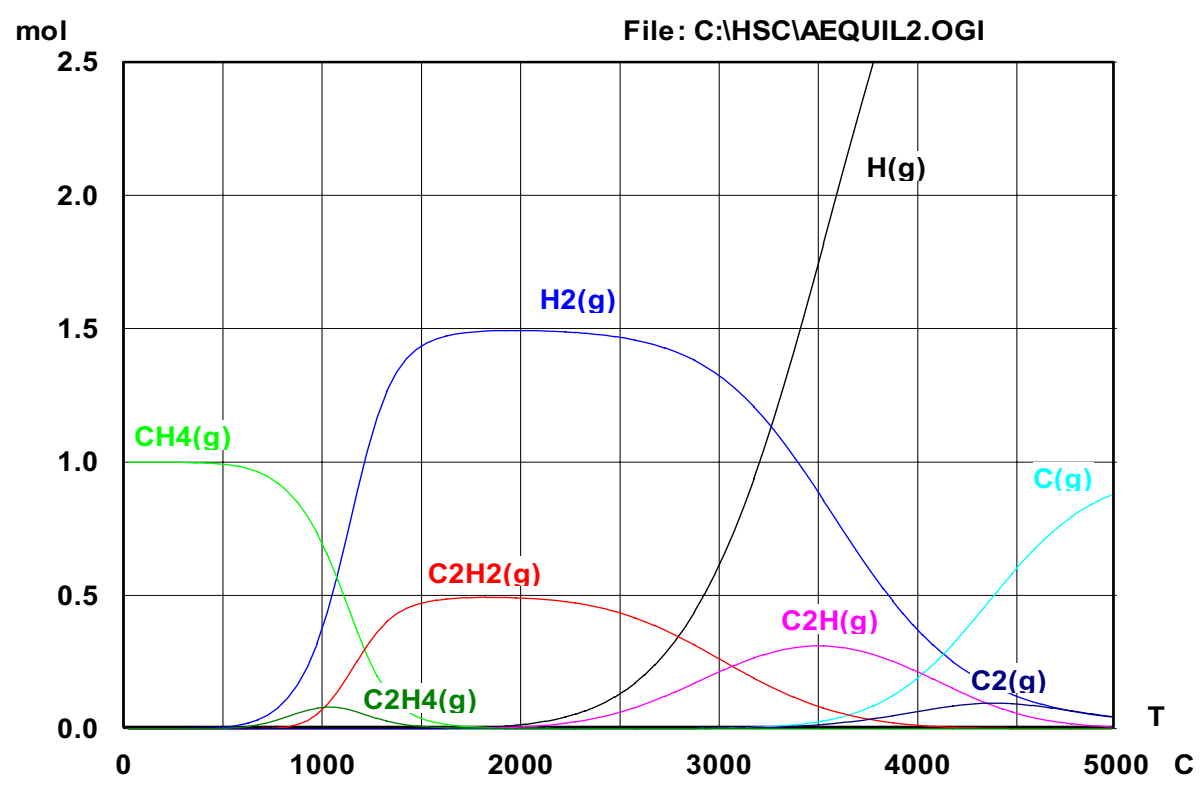

Figure 1-3. Simplified equilibrium diagram for methane where the solid phase of carbon is not included as a species. 
Conversion efficiency $(\mathrm{CE})$ is defined as

$$
C E=\left[1-\frac{\left.\dot{Q}_{C H 4}^{P}\right\rceil}{\dot{Q}_{C H 4}^{i n}} \times 100\right.
$$

where $Q_{\mathrm{CH}_{4}}$ is the volumetric flow rate of methane at standard temperature and pressure, the superscripts "P" and "in" denote the product stream and process feedstock inflow respectively. For complete conversion, $\mathrm{CE}$ is $100 \%$. The definition of conversion efficiency can be generalized to address other feedstocks that contain significant amounts of other hydrocarbons.

Yield (y) is generally defined as

$$
\mathrm{y}=\frac{\text { mass carbon containedin a particularproduct }}{\text { mass carbon input in feedstockinflow }} \times 100 \text {. }
$$

For $100 \%$ selectivity, that is all of the carbon input is converted to a single product, the yield is $100 \%$. Two yield numbers are particularly important, the yield of acetylene, which for methane feedstock is

$$
y_{\mathrm{C}_{2} \mathrm{H}_{2}}=\frac{2 \cdot \dot{Q}_{\mathrm{C} 2 \mathrm{H} 2_{2}}^{P}}{\dot{Q}_{\mathrm{CH} 4}^{i n}}(100)
$$

and the yield for all other hydrocarbons which may be considered singly or as a group

$$
\mathrm{yHC}=\frac{\mathrm{n} \cdot \dot{\mathrm{Q}}_{\mathrm{CxHy}}^{\mathrm{P}}}{\dot{Q}_{\mathrm{CH} 4}^{\text {in }}}(100) \text { where } \mathrm{C}_{\mathrm{x}} \mathrm{H}_{\mathrm{y}} \neq \mathrm{C}_{2} \mathrm{H}_{2} \text {. }
$$

The yield of acetylene can be normalized to account for the fact that methane conversion is not complete. The yield, defined in this manner, is actually a measure of acetylene selectivity. The normalized yield is

$$
y_{\mathrm{C}_{2} \mathrm{H}_{2}}^{N}=\frac{y_{\mathrm{C}_{2} \mathrm{H}_{2}}}{\mathrm{CE}} .
$$

Finally, process performance can be compared on the basis of energy consumption per unit of acetylene produced, or the specific energy requirement (SER). For the process suggested in Figure 1-3, $98.5 \%$ yield, $100 \%$ conversion efficiency, a product stream at approximately $2000{ }^{\circ} \mathrm{C}$ and ignoring all thermal losses or inefficiencies, the specific energy requirement is $\mathrm{SER} \approx 7.9 \frac{\mathrm{kW}-\mathrm{hr}}{\mathrm{kg}-\mathrm{C}_{2} \mathrm{H}_{2}}$. This number increases with lower yield and conversion efficiency and with unavoidable thermal losses and electrical inefficiencies. Lowering the temperature of the product stream can decrease the specific energy requirement at least until the point at which yield and conversion efficiency are significantly adversely affected.

The Huels process as described in Gladish (1962) has the following characteristics for natural gas feed in a nominally $8 \mathrm{MW}$ reactor at a feed rate of $2344 \mathrm{Nm}^{3}$ natural gas per hour. The conversion efficiency was $70.5 \%$, the yield of acetylene was $51.4 \%$, the yield of all other hydrocarbons (including 
unconverted methane) was $45.9 \%$ and the yield of solid carbon soot was $2.7 \%$. The normalized acetylene yield, or selectivity which is normalized or adjusted for the actual measured methane conversion efficiency becomes $72.9 \%$. The measured specific energy requirement was $12.1 \frac{\mathrm{kW}-\mathrm{hr}}{\mathrm{kg}-\mathrm{C}_{2} \mathrm{H}_{2}}$.

The fundamental question that is addressed in this study is whether the modest methane conversion efficiencies, acetylene yields and selectivities and specific energy requirements observed in the original Huels process can be substantially improved upon. Central to this issue is the identification of mechanisms that are responsible for lowering the observed conversion efficiency and yield values and investigation of possible solutions. The two immediately apparent possibilities are: (1) steep radial temperature gradients and poor mixing in the reactor; and (2) a quenching process that is not rapid enough to freeze the composition of the product stream.

Temperature gradients and poor mixing lead to a non-uniform distribution of temperatures in the reactor. The composition of the product stream is a function of kinetics or rate of reaction and also on the temperature non-uniformities. These effects can lead to significant variations in product stream composition. If the quench process is too slow or delayed, the acetylene produced can thermally decompose to solid carbon soot (Frenklach and Wang, 1994 and Lindstedt, 1992) or may further react, principally on hot surfaces, to form benzene and heavier hydrocarbons. These issues are experimentally addressed in a nominally $75 \mathrm{~kW}$ laboratory reactor system. The issue of non-uniform temperatures is examined using a carbon lined "hot wall" reactor configuration, which minimizes the radial temperature gradients and heat loss from the reactor section. The issue of poor mixing is addressed through the use of a confined channel injector design, which under a separate project, has been shown to provide good mixing of reactants into a plasma stream (Fincke, et al., 1993). The effect of quench rate is addressed by the incorporation of a supersonic quench nozzle into the test apparatus, just downstream of the reactor section (Detering, Donaldson, Fincke, and Kong, 1998). In the supersonic nozzle, the hot gases in the reactor section are rapidly expanded to a lower pressure. In this process thermal energy is converted to kinetic energy and the mixture is rapidly cooled. The process is sometimes referred to as an aerodynamic quench. Quench rates of $10^{7}-10^{8}{ }^{\circ} \mathrm{C} / \mathrm{s}$ or two to three orders of magnitude greater than those reported in the original Huels process are achievable.

In the following section a brief review of the available literature is given. While a wide variety of feedstocks have been historically examined, including liquid hydrocarbons and coal, the emphasis of this review will be those works which utilize methane or natural gas as the primary feedstock. The experimental apparatus and experimental results both with and without the aerodynamic quench nozzle are presented next and the measured specific energy requirement data reviewed. Current results are then compared to prior results from the literature. A survey of commercial plasma equipment applicable to the thermal plasma conversion of methane to acetylene is provided in Appendix A. 


\section{PRIOR WORK}

Relevant results from the available literature on acetylene derived from hydrocarbons by the electric arc process are tabulated in Table 2-1. This table is restricted to investigations into use of methane or natural gas as the process feedstock. The earliest results are reported by Gladisch (1962) and date to 1940 . The plant, which was developed by Chemische Werke Huels, originally used the low boiling components of the motor fuel industry as raw material although feedstocks ranging from natural gas (Gladisch, 1962) to coal (Miller and Peuckert, 1983; Peuckert and Miller, 1985) have been examined. The process is generally referred to as the Huels process and was briefly summarized in the introduction. A similar process with reactors of similar size ( 9 MW) was built by DuPont and operated between 1963 and 1968 supplying acetylene produced from liquid hydrocarbon sources to a neoprene plant (Holmes, 1969). The process was also reportedly demonstrated at the pilot-plant scale using methane feed. The plant-scale operation was limited to liquefied petroleum gas or liquid hydrocarbon distillates. The size of the DuPont pilot scale process is not reported in Holmes (1969). In the DuPont process the arc was magnetically rotated while in the original Huels process the arc is "swirl stabilized" by tangential injection of gases. In the DuPont process all feedstock, diluted with hydrogen, passed through the arc column; in the Huels process a fraction of the reactants are injected downstream of the arc. The major aspects of the two processes, as are available, are summarized in Table 2-2. 


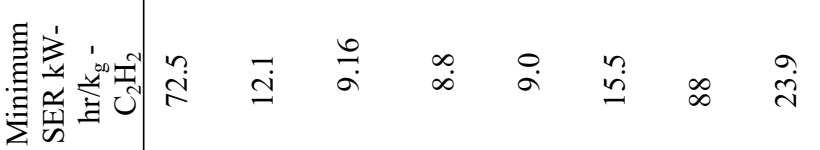

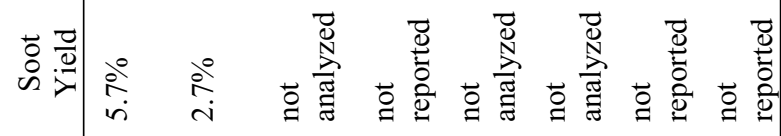

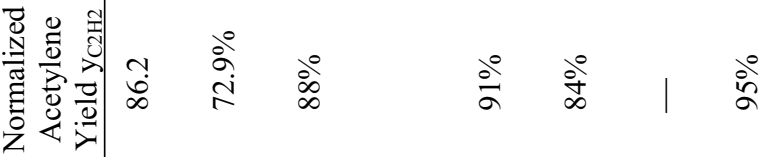

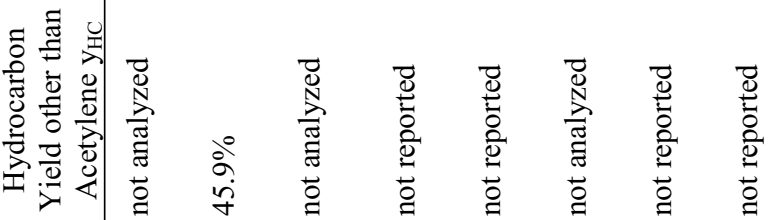

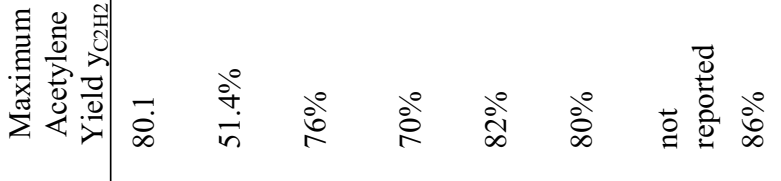

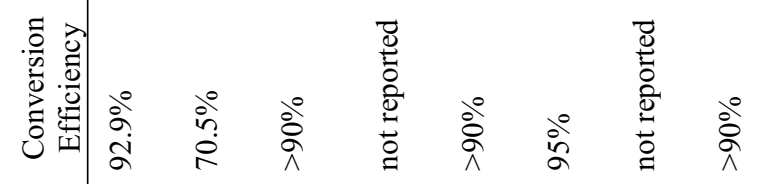

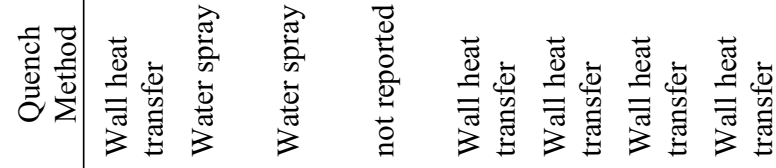

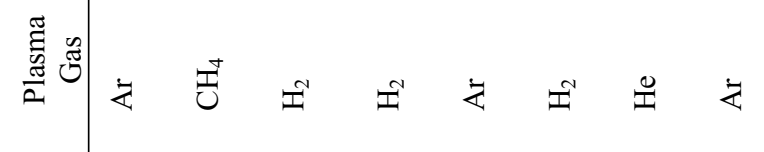

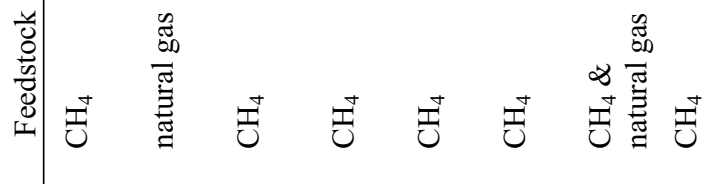

:

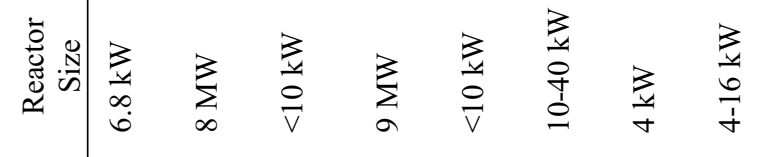

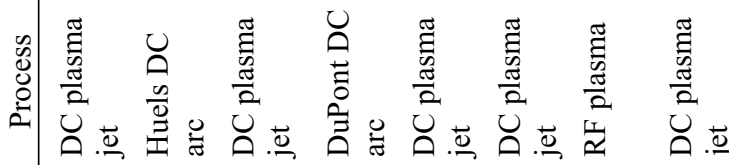

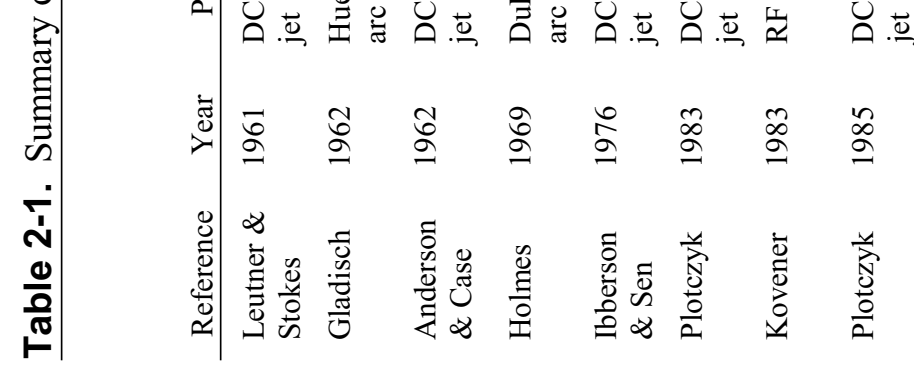


Table 2-2. Comparison of Huels and DuPont processes.

\begin{tabular}{lll}
\hline & \multicolumn{1}{c}{$\begin{array}{c}\text { Huels Process } \\
\text { (Gladisch, 1962) }\end{array}$} & \multicolumn{1}{c}{$\begin{array}{c}\text { DuPont Process } \\
\text { (Holmes, 1969) }\end{array}$} \\
\hline Power level & $8 \mathrm{MW}$ & $9 \mathrm{MW}$ \\
Arc gas & $\mathrm{H}_{2}+\mathrm{CH}_{4}$ & $\mathrm{H}_{2}+\mathrm{CH}_{4}$ \\
Downstream injection & yes & no \\
Stabilization & swirl & magnetic rotation \\
Pressure & not stated & 200 torr \\
Quench & water spray & not stated \\
\hline
\end{tabular}

When operated on methane, both the reported yield and specific energy requirement of the DuPont process appear to be somewhat improved over that of the Huels process, $70 \%$ vs. $50 \%$ for yield and SER of 8.8 vs. $12.1 \frac{\mathrm{kW}-\mathrm{hr}}{\mathrm{kg}-\mathrm{C}_{2} \mathrm{H}_{2}}$. Because the reported yields for the DuPont process for hydrocarbon feedstock up to $\mathrm{C}_{10}$ are reported to be in the range of $65-75 \%$ vs. $50 \%$ for the Huels process, the data suggest that there is, in fact, a fundamental difference between the Huels and DuPont processes and that the higher yields for methane are not somehow due to the use of a smaller scale (pilot-scale) reactor. The amount of hydrogen introduced as plasma gas may have an effect on the reported results as may pressure and magnetic arc rotation. Lower pressure and higher hydrogen concentrations may inhibit soot and the formation of other hydrocarbons while magnetic arc rotation may lead to a better "stirred" reactor. Little additional data is currently available to help differentiate between the performance of the two processes. The Huels and DuPont processes represent the only industrial scale demonstrations of the conversion of methane to acetylene by the plasma arc process.

In addition to the Huels and DuPont work there have been a number of laboratory scale investigations generally conducted at less than $10 \mathrm{~kW}$ power levels. These investigations have generally utilized DC plasma jets. The electrical discharge heats $\mathrm{Ar}, \mathrm{H}_{2}$ or a mixture of the two. In one case a radio frequency plasma is used and the plasma gas is helium. Methane (or natural gas) is injected downstream of the discharge and mixes with the hot gas jet. The predominant method of quenching is wall heat transfer to cooling water. Reported conversion efficiencies are generally in excess of $90 \%$ while acetylene yields range from 76 to $86 \%$. The yield of other hydrocarbons or solid carbon soot is generally not reported in the literature cited. The measured specific energy requirement ranges from a high of $88 \frac{\mathrm{kW}-\mathrm{hr}}{\mathrm{kg}-\mathrm{C}_{2} \mathrm{H}_{2}}$ to a low of $9 \frac{\mathrm{kW}-\mathrm{hr}}{\mathrm{kg}-\mathrm{C}_{2} \mathrm{H}_{2}}$. This value should be compared to a theoretical value of $7.9 \frac{\mathrm{kW}-\mathrm{hr}}{\mathrm{kg}-\mathrm{C}_{2} \mathrm{H}_{2}}$ for a product stream at $2000{ }^{\circ} \mathrm{C}, 100 \%$ acetylene yield and $100 \%$ conversion and thermal efficiency. Because DC plasma devices, particularly small scale ones with low volume to heat loss area ratio, are rarely better than $70-85 \%$ thermally efficient, that is $70-85 \%$ of the discharge power is deposited in the gas stream, the rest is lost to cooling water, any reported specific energy requirement less than about $9.5 \frac{\mathrm{kW}-\mathrm{hr}}{\mathrm{kg}-\mathrm{C}_{2} \mathrm{H}_{2}}$ should be critically regarded. As discharges and plasma reactors are scaled to larger sizes, with more favorable volume to surface area ratios, the system thermal efficiency can often be somewhat improved. At larger scales, process heat recovery and preheating of plasma and reactant gases can also lower specific energy requirements. 


\section{CURRENT APPROACH}

The configuration of the test apparatus addresses the issues identified as possible causes of measured yields that are smaller than theoretically possible. This configuration includes a four port injector of proven geometry (Fincke, et al., 1993), the provision for supersonic expansion through a converging-diverging nozzle to greatly increase quench rates, and a carbon lined reactor which provides residence time for reactions to take place while minimizing radial temperature gradients.

The overall Process and Instrumentation Diagram (P\&ID) for the experimental apparatus is shown in Figure 3-1. In general, the instrumentation and component identifications follow the convention that $T$ is a temperature, $\mathrm{P}$ a pressure, $\mathrm{FM}$ a flow meter, $\mathrm{V}$ a valve, and $\mathrm{cw}$ denotes cooling water. A photograph of the test assembly appears in Figure 3-2. The detail of the torch, injector, reactor and nozzle assembly appears in Figure 3-3, and a photograph of the actual apparatus in Figure 3-4. The nozzle assembly could be removed and replaced with a straight copper section of the same inside diameter as the downstream piping to provide baseline data to determine the effectiveness of the aerodynamic quench concept. In addition to the measurements noted on the P\&ID diagram, a gas chromatograph is used to analyze the composition of the product stream.

All instrumentation except for the gas chromatograph is directly interfaced to a data acquisition system for continuous recording of system parameters during a test run. Once the specified process power levels, pressures, and gas flow rates are established, the gas stream is continuously sampled by the gas chromatograph for a period of 7 minutes before the chromatograph gas sample is acquired to ensure that a representative sample is obtained. This sampling period represents approximately three times the time required to completely purge the sample line. The pressure downstream of the quench nozzle is controlled by a mechanical vacuum pump and a flow control valve, V12. Depending on the test conditions, the test pressure can be independently adjusted between atmospheric pressure and approximately 100 torr. The experiment reaches steady state in a period of 1 minute or less. Steady state operation is verified by a continuously reading residual gas analyzer (RGA). All cooling water flow rates and inlet and outlet temperatures are monitored and recorded allowing a complete system energy balance to be calculated. The plasma gases are a mixture of $\mathrm{Ar}$ and $\mathrm{H}_{2}$; methane or natural gas is injected downstream in a confined channel transverse jet injector. The DC plasma torch that is currently used will not operate for extended periods of time on pure hydrogen without severe anode erosion, hence all test data is acquired using at least some Ar plasma gas. The use of Ar, which is inert and does not participate chemically in the process, has the advantage that it provides a built in reference for validating the overall process mass balance; this will be addressed in more detail below. The processing of methane directly in the discharge is precluded by the severe erosion of the tungsten cathode via the formation of volatile tungsten carbides. The two most critical aspects of the experiment are the chemical analysis of the product stream and the overall mass balance. These two measurement systems are described separately below. The uncertainty estimates for the various measurements and derived quantities are also provided.

\subsection{Mass Balance}

The flow rates of the feed gases are measured by MKS Model 1559A mass flow controllers. These meters were factory calibrated. The factory calibrations have been verified by the INEEL standards laboratory. The actual volumetric flow rate of the product gas stream is measured by a Flow Technology Model FT-20AEXA-GEH-1 turbine meter. This meter was also factory calibrated and performance verified by the INEEL standards laboratory. Because this meter must operate in a reduced pressure 


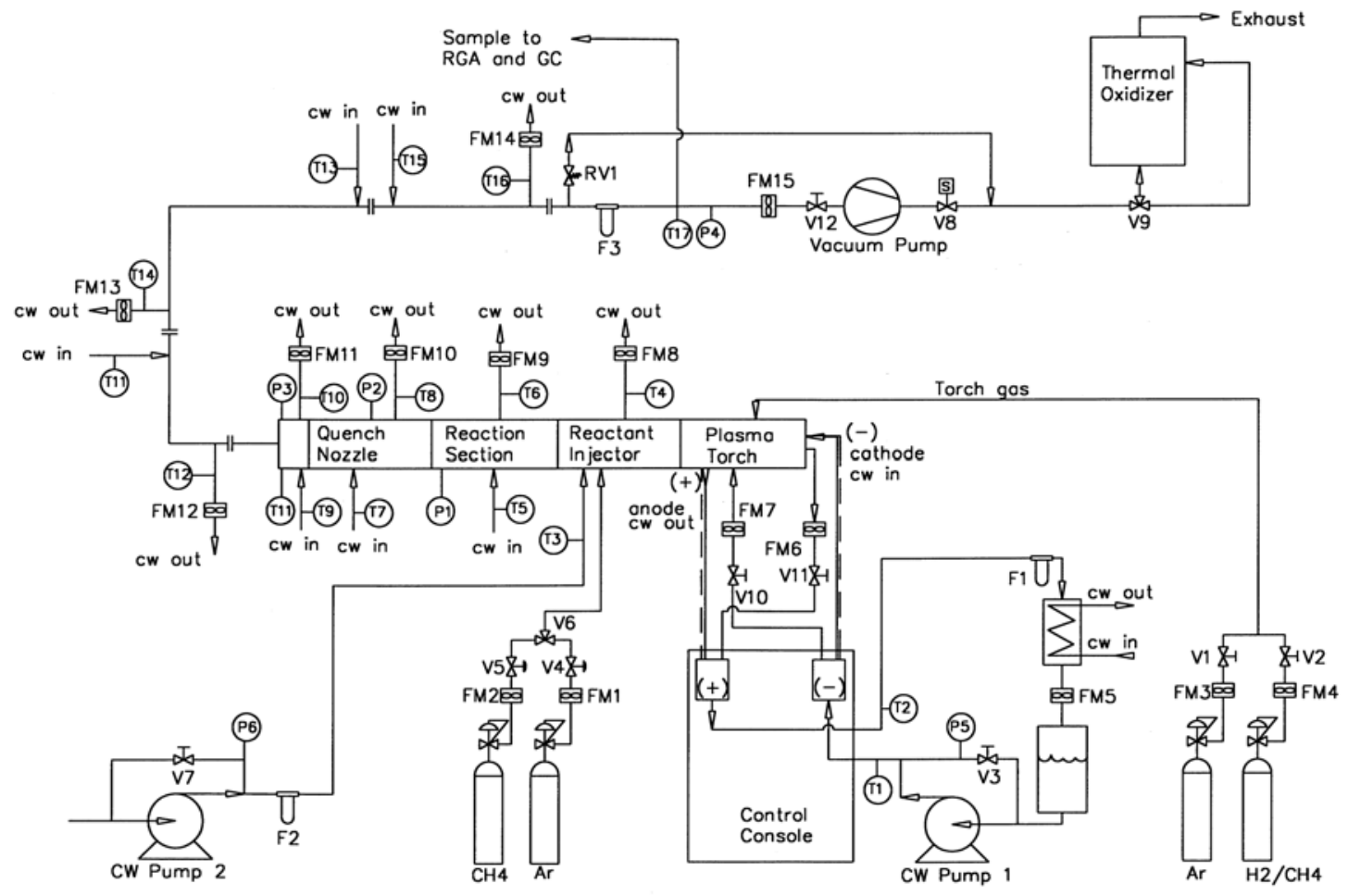

Figure 3-1. Process and Instrumentation Diagram.

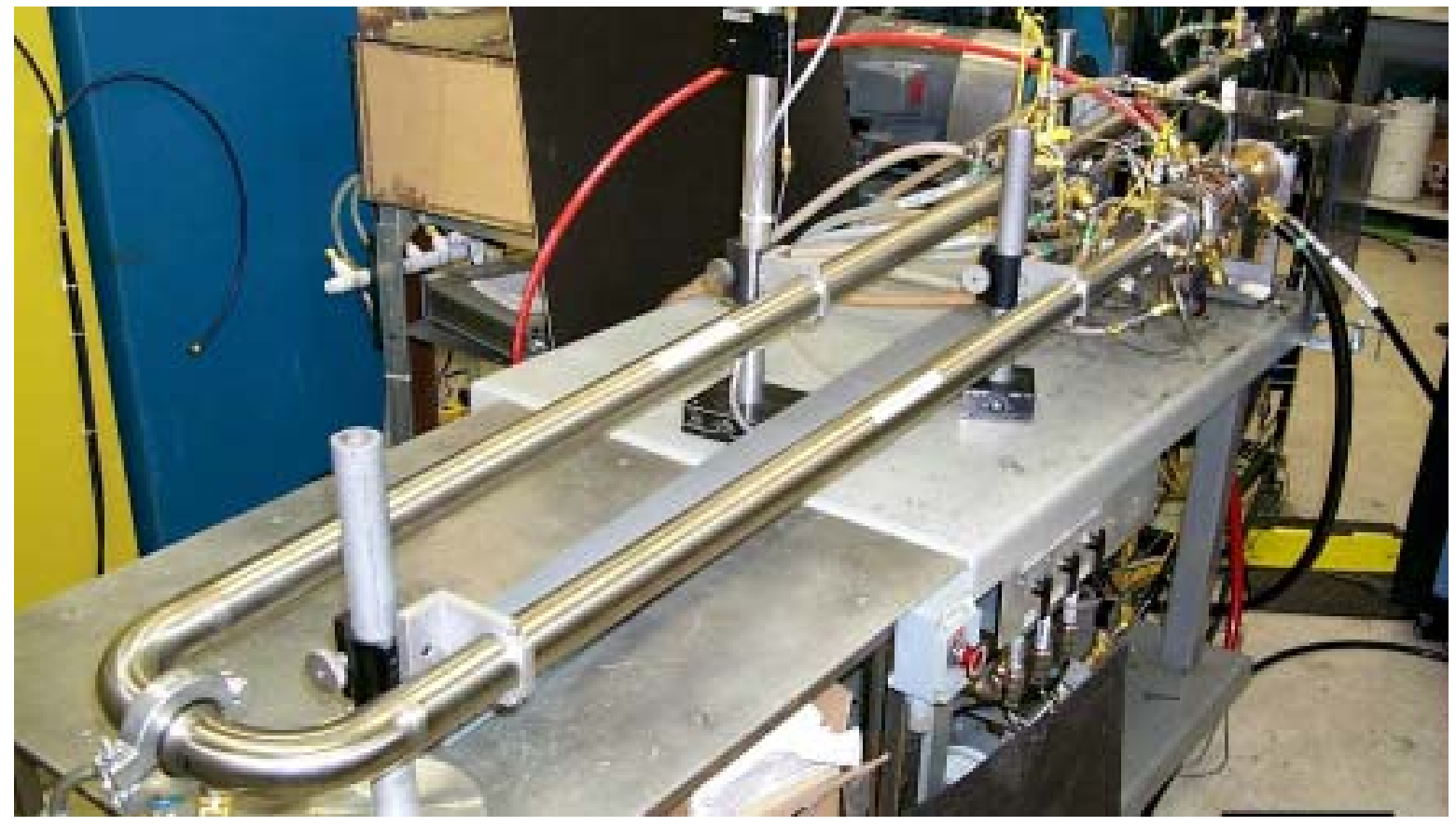

Figure 3-2. Photograph of test apparatus. 


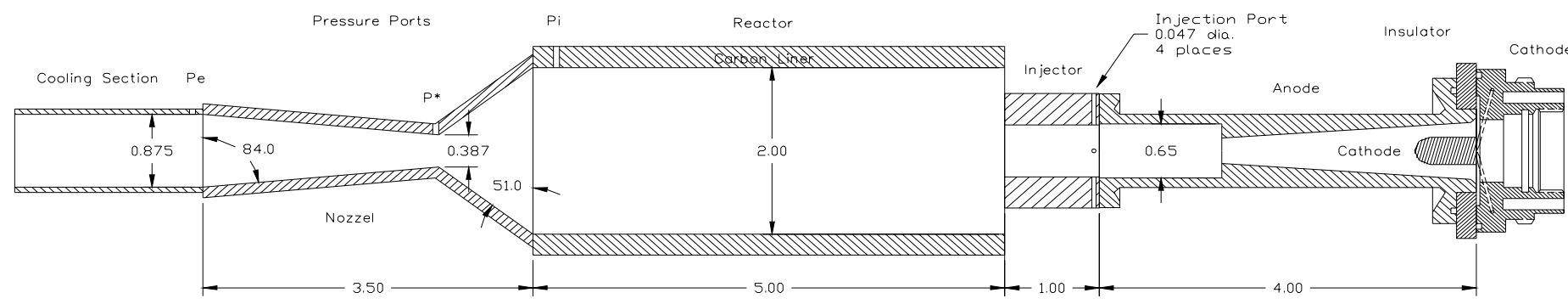

Figure 3-3. Schematic of torch, injector, reactor and nozzle assembly, flow is right to left. All dimensions are in inches.

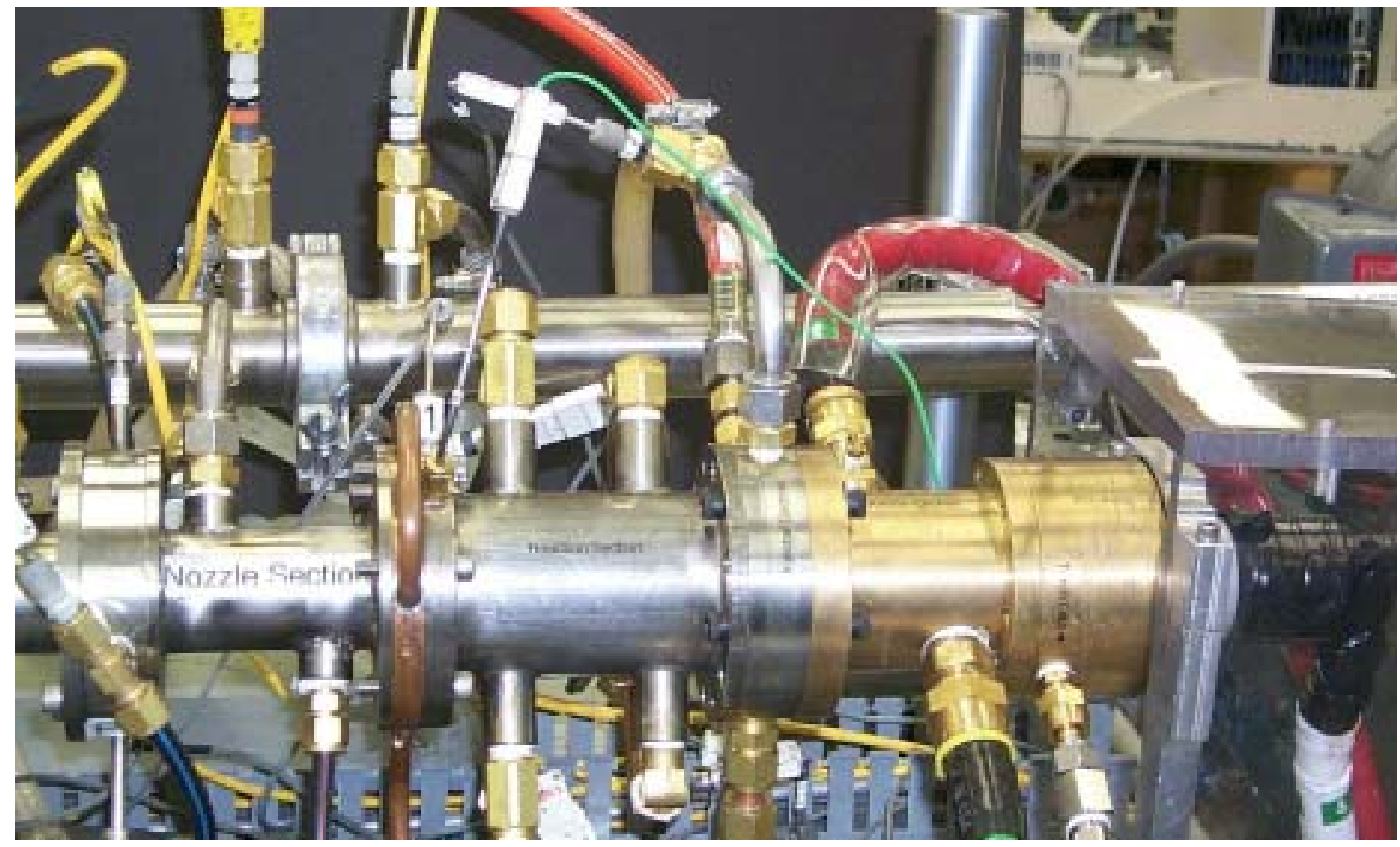

Figure 3-4. Photograph of torch, injector, reactor and nozzle assembly, flow is right to left. 
environment, a radio frequency pickup is used to avoid the magnetic drag associated with a conventional magnetic pickup. Pressure and temperature were measured just upstream of the turbine meter. Figure 3-5 contains a comparison of the volumetric flow rates, given in standard liters per minute (slm), of argon and argon plus hydrogen measured by the MKS mass flow controllers and the downstream turbine meter for cold flow at reduced pressure. Figure 3-6 shows the overall mass balance error in percent of meter reading. In general, the agreement is excellent and consistent with the meter specifications. During actual testing the downstream product volumetric flow rate measurement performed satisfactorily as long as the meter was kept clean. Invariably some ultra fine carbon produced in the experiment would deposit in the meter bearings and cause the meter to under report the actual flow rate. In spite of frequent cleanings the meter would sometimes slow or even stop turning during a particular experimental run; consequently this data is not always available for all runs. The use of argon throughout the experimental campaign provided a separate and independent means of estimating product stream volumetric flow rate. Because the argon is inert and does not participate chemically in the overall reaction, the mass flow rate of argon in the produced stream is always the same as the input argon mass flow rate. Using the gas chromatograph data, the total exit volumetric flow rate can be estimated from the ratio of the input argon volumetric flow rate given at standard temperature and pressure $\dot{Q}_{A r}$, and the measured mole fraction of argon $[\mathrm{Ar}]$ in the product stream obtained from the gas chromatograph.

$$
\dot{Q}_{\text {total }}=\frac{\dot{Q_{A r}}}{[A r]}
$$

The measurement can always be used as an independent check of the downstream flow meter, and as an independent measurement of product volumetric flow rate.

\subsection{Chemical Product Analysis}

The composition of the product stream is analyzed by a Hewlett-Packard Series 6890 Model G1540A gas chromatograph. Sampling is through a 1/8th-inch stainless steel line. Because the experiment generally operates at reduced pressure, the sample gas is raised to atmospheric pressure by a stainless steel diaphragm pump. Sample gas continuously flows through the sampling system to the gas chromatograph for a minimum period of 7 minutes after the experiment has reached steady state. This ensures that a valid and representative sample of the product gas mixture has been obtained. Care is taken to maintain the sample pressure at the local atmospheric pressure, the same pressure at which the gas chromatograph was calibrated. Calibration of the gas chromatograph was accomplished using certified calibration mixtures and verified against laboratory prepared mixtures using process gases and a pressure transducer. It was found that multi-point non-linear calibrations were required to obtain acceptable measurement performance over the entire range of anticipated tests and associated concentrations. The assigned single sigma measurement uncertainty of $\pm 4 \%$ of reading was experimentally determined by repeatedly sampling and analyzing known gas mixtures.

\subsection{Uncertainty Estimates}

In this section the uncertainties in the derived quantities of conversion efficiency and yield along with the system mass balances are presented and their magnitude estimated from the uncertainties in the primary measurements. All results are tabulated in the tables below. The estimated uncertainties are compared to an example of actual measurement performance. The uncertainties assigned to the plasma gas and methane/natural gas reactant flow rates are obtained from the flow meter manufacturer. These uncertainties are consistent with independent verification of flow meter calibration conducted in the INEEL standards laboratory. Pressure is measured by a Baraton Type 107 pressure transducer and 


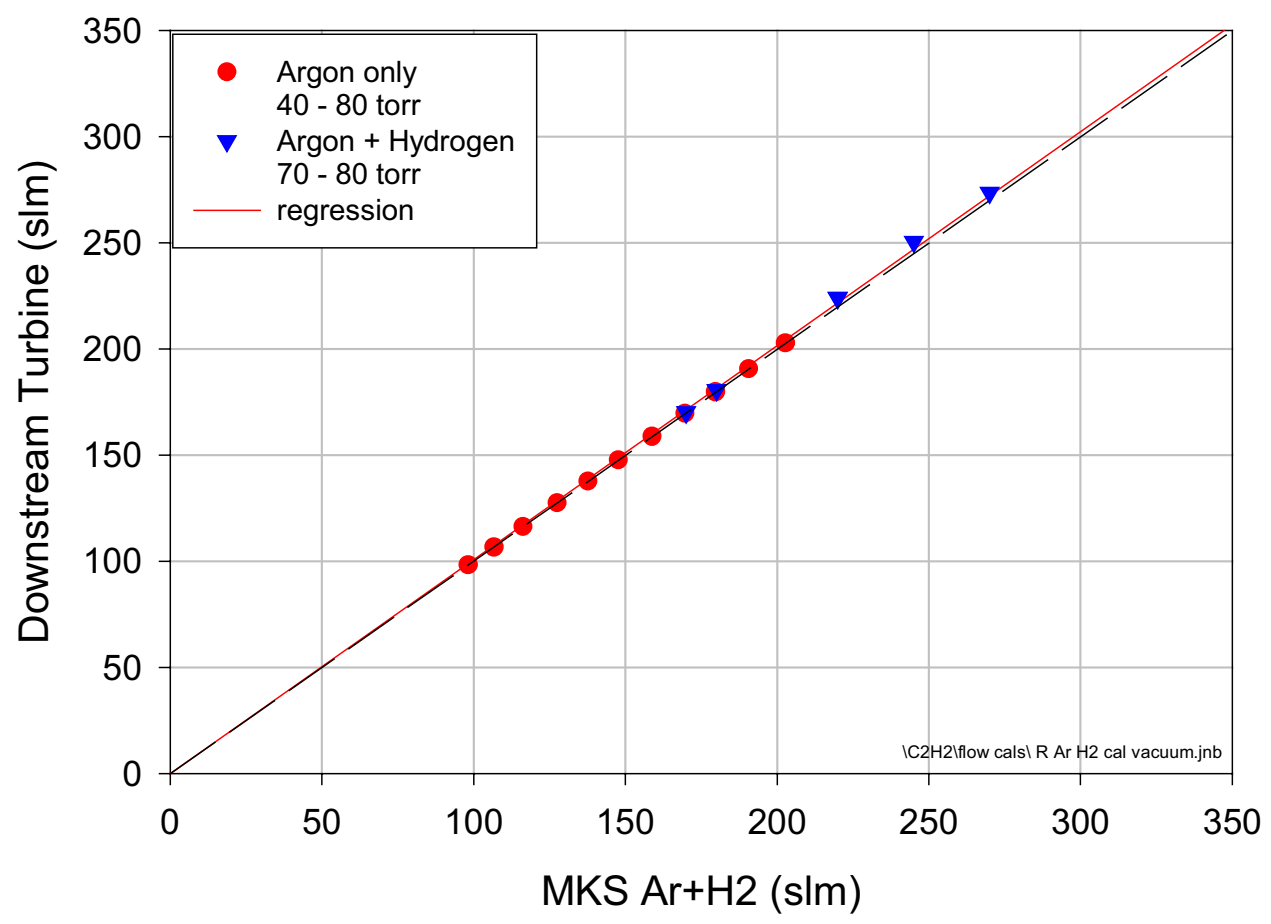

Figure 3-5. Cold flow overall mass balance validation. (The dashed line is the 45-degree line of perfect agreement and the solid line is the least-squares fit to the data.)

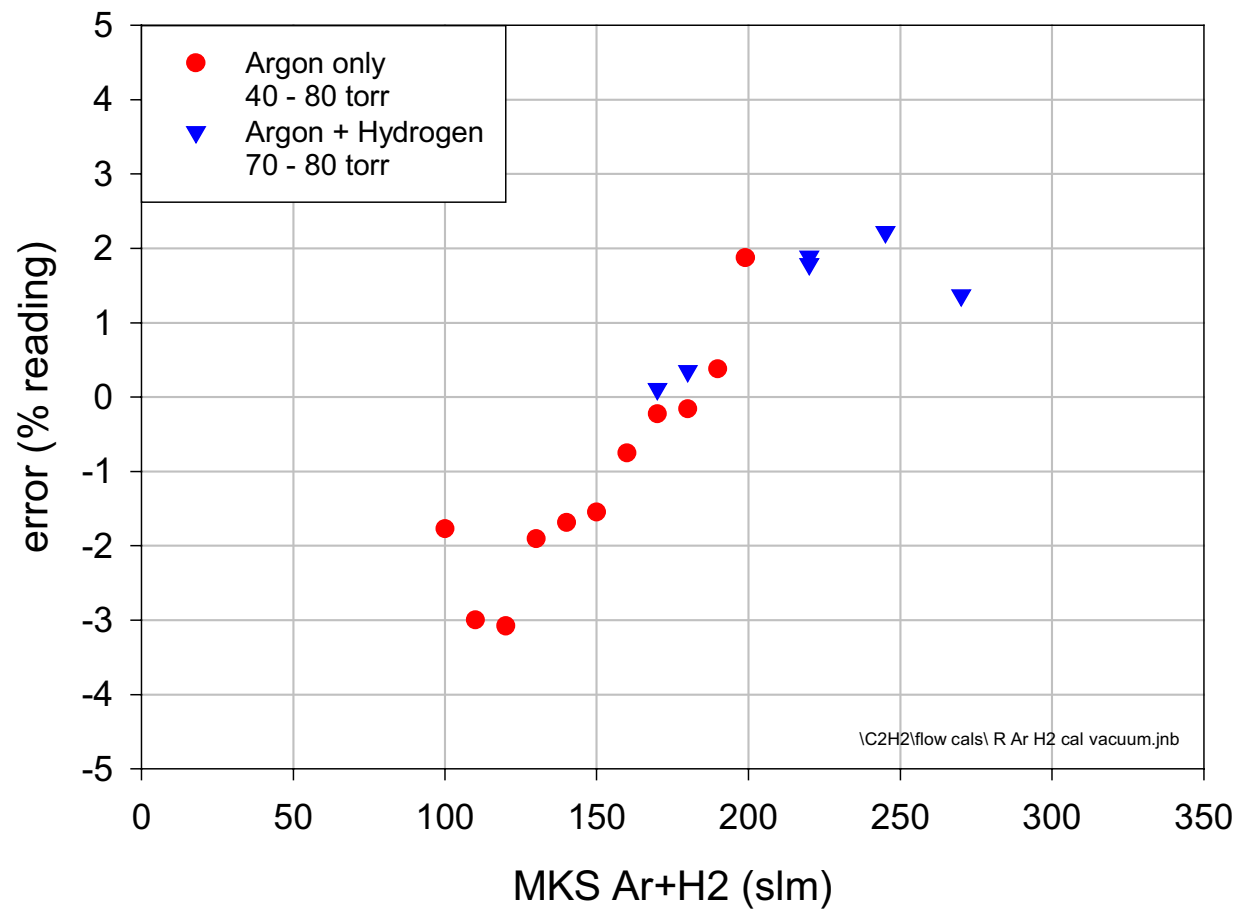

Figure 3-6. Cold flow overall mass balance error in percent of reading. 
temperature is obtained from a type K thermocouple and Omega model DP116 readout with integrated reference junction. The uncertainties assigned to the pressure and temperature measurements are also consistent with the manufacturer specification of $\pm 0.5 \%$ of range for pressure and $\pm 1{ }^{\circ} \mathrm{C}$ for temperature. All channels of data acquisition have been "end-to-end" calibrated using a NIST traceable voltage or frequency standard as required.

The uncertainties assigned to the downstream turbine meter are more problematic. While the downstream turbine meter is capable of $\pm 2 \%$ of range performance, as observed in the cold flow comparison data, Figures 3-5 and 3-6, its performance often degrades during a test run because of the deposition of fine carbon particles in the bearings. This occurs even though the turbine meter is located downstream of a filter assembly. Due to the very small size of the carbon produced (measured mean diameter is $30 \mathrm{~nm}$ or less for unagglomerated particles), this filter invariably passes some carbon which can deposit in the turbine. This increases the bearing drag causing the turbine to under report the actual flow rate. This degradation is generally obvious from the slow decrease in apparent volumetric flow rate with time in some tests. In some instances the turbine even stops turning. Once the onset of degradation in performance is observed the turbine meter is removed, completely disassembled, and cleaned in an ultrasonic bath. This is generally sufficient to restore performance. Unfortunately performance degradation disqualifies the turbine data for a particular run. The runs are generally repeated with the newly cleaned turbine meter. Even when the turbine meter data is disqualified, data can still be extracted from the test run by estimating the total product volumetric flow rate from the GC data and the known flow rate of argon. Because of the sometimes unknown degree of performance degradation of the turbine flow meter, the uncertainty assigned to the volumetric flow rate is $\pm 5 \%$ rather than the more optimistic \pm $2 \%$ demonstrated in the cold flow data. A summary of the assigned uncertainties in the primary measurements appears in Table 3-1. All uncertainties are stated as single-sigma values, or one standard deviation.

Table 3-1. Summary of estimated uncertainties in primary measurements.

\begin{tabular}{|c|c|c|}
\hline Quantity & $\begin{array}{c}\text { Uncertainty Type } \\
\% \text { of Range or Reading }\end{array}$ & Assigned $1 \sigma$ Uncertainty \\
\hline Temperature & - & $\pm 1^{\circ} \mathrm{C}$ \\
\hline Pressure & range & $\pm 0.5 \%$ \\
\hline Product volumetric flow rate & range & $\pm 5 \%$ \\
\hline Plasma gas volumetric flow rate & range & $\pm 1 \%$ \\
\hline Reactant gas volumetric flow rate & range & $\pm 1 \%$ \\
\hline GC molar concentration & reading & $\pm 4 \%$ \\
\hline
\end{tabular}


The actual measured volumetric flow rate is converted to standard conditions ( 1 atmosphere and $\left.0{ }^{\circ} \mathrm{C}\right)$ by

$$
\dot{Q}_{S T P}=\dot{Q}_{\text {actual }}\left(\frac{760}{P_{\text {test }}}\right)\left(\frac{273}{T_{\text {test }}+273}\right)
$$

where pressure is in torr and temperature in degree centigrade.

The single sigma uncertainty in $\dot{Q}_{S T P}$ then becomes

$$
\frac{\sigma \dot{Q}_{S T P}}{\dot{Q}_{S T P}}=\left[\left(\frac{\sigma \dot{Q}_{\text {actual }}}{\dot{Q}_{\text {actual }}}\right)^{2}+\left(\frac{\sigma P_{\text {test }}}{P_{\text {test }}}\right)^{2}+\left(\frac{\sigma T_{\text {test }}}{T_{\text {test }}}\right)^{2}\right]^{1 / 2}
$$

When $\dot{Q}_{\text {actual }}$ is estimated from the GC molar concentration data and the known argon flow rates the expression for $\dot{Q}_{S T P}$ becomes

$$
\dot{Q}_{S T P(A r)}=\frac{\dot{Q}_{A r}}{[A r]}
$$

The uncertainty in $\dot{Q}_{\text {actual }(A r)}$ is

$$
\frac{\sigma \dot{Q}_{S T P(A r)}}{\dot{Q}_{S T P(A r)}}=\left[\left(\frac{\sigma \dot{Q}_{A r}}{\dot{Q}_{A r}}\right)^{2}+\left(\frac{\sigma[A r]}{[A r]}\right)^{2}\right]^{1 / 2}
$$

where $\dot{Q}_{A r}$ is the measured argon volumetric flow rate and [Ar] is the molar fraction of Ar in the product stream obtained from the GC data.

The conversion efficiency, for pure methane injection, is defined as

$$
C E=1-\frac{\left[\mathrm{CH}_{4}\right] \dot{Q}_{S T P}}{\dot{Q}_{\mathrm{CH}_{4}}}=1-y_{\mathrm{CH}_{4}}
$$

where $\left[\mathrm{CH}_{4}\right]$ is the molar fraction of methane in the product stream obtained from the GC and $\dot{Q}_{\mathrm{CH}_{4}}$ is the methane injection rate. The last term on the right hand side is the yield of methane in the product stream. The uncertainty in methane yield becomes 


$$
\frac{\sigma_{\mathrm{CH}_{4}}}{y_{\mathrm{CH}_{4}}}=\left[\left(\frac{\sigma\left[\mathrm{CH}_{4}\right]}{\left[\mathrm{CH}_{4}\right]}\right)^{2}+\left(\frac{\sigma \dot{Q}_{S T P}}{\dot{Q}_{S T P}}\right)^{2}+\left(\frac{\boldsymbol{\sigma} \dot{Q}_{\mathrm{CH}_{4}}}{\dot{\bullet}_{\mathrm{CH}_{4}}}\right)^{2\rceil^{1 / 2}}\right.
$$

The corresponding uncertainty in conversion efficiency becomes

$$
\frac{\sigma C E}{C E}=\left(\frac{\sigma y_{C H_{4}}}{y_{C_{4}}} \frac{y_{C H_{4}}}{1-y_{C H_{4}}}\right.
$$

which is dependent on the measured yield which ranges from $<0.5 \%$ to $30 \%$. Table $3-3$ contains the estimated maximum uncertainty; for CE near unity the uncertainty is small. Acetylene yield (for pure methane injection) is defined as

$$
y_{C_{2} \mathrm{H}_{2}}=\frac{2\left[\mathrm{C}_{2} \mathrm{H}_{2}\right] \dot{Q}_{S T P}}{\dot{Q}_{\mathrm{CH}_{4}}}
$$

where $\left[\mathrm{C}_{2} \mathrm{H}_{2}\right]$ is the molar fraction of acetylene in the product stream measured by the GC. The uncertainty in acetylene yield becomes

$$
\frac{\sigma_{C_{2} H_{2}}}{y_{C_{2} H_{2}}}=\left[\left(\frac{\sigma\left[C_{2} H_{2}\right]}{\left[C_{2} H_{2}\right]}\right)^{2}+\left(\frac{\sigma \dot{Q}_{S T P}}{\dot{Q}_{S T P}}\right)^{2}+\left[\frac{\sigma \dot{Q}_{C H_{4}}}{\dot{Q}_{C H_{4}}}\right]^{2}\right]^{1 / 2}
$$

The yield and estimated uncertainty of all other hydrocarbons is defined in a completely analogous manner and can be generalized if the reactant contains carbon bearing species other than methane.

The expressions for the total mass balance, the hydrogen mass balance, and the carbon mass balances are given below, where the species considered are shown in Table 3-2. In all of the expressions $M W_{i}$ is the molecular weight of species $i, \# C_{i}$ is the number of carbon atoms contained in species $i, \# H_{i}$, is the number of $\mathrm{H}$ atoms contained in species $\mathrm{i}$, and $\mathrm{X}_{\mathrm{i}}$ is the molar concentration obtained from the GC. The expression for the total mass flow rate becomes

$$
\dot{m}_{t}=\sum_{i} \frac{M W_{i}}{22.4}\left[X_{i}\right] \dot{Q}_{S T P}
$$

where the constant 22.4 is in standard litres per gm-mole (CGS units). The expression for the amount of carbon in the gas-phase product stream is

$$
\dot{m}_{C}=\sum_{i} \frac{\# C_{i} \cdot 12}{22.4}\left[X_{i}\right] \dot{Q}_{S T P}
$$

and the expression for the amount of hydrogen in the product stream is 
$\dot{m}_{H}=\sum_{i} \frac{\# H_{i} \cdot 1}{22.4}\left[X_{i}\right] \dot{Q}_{S T P}$

The corresponding expressions for the uncertainties in the total, gas phase carbon and hydrogen mass flows are

$$
\begin{aligned}
& \frac{\sigma \dot{m}_{t}}{\dot{m}_{t}}=\left[\left(\frac{\sigma \dot{Q}_{S T P}}{\dot{Q}_{S T P}}\right)^{2}+{ }_{i}\left(\frac{M W_{i} \cdot \sigma\left[X_{i}\right]}{M W_{i}\left[X_{i}\right]}\right)^{2}\right]^{1 / 2} \\
& \frac{\sigma \dot{m}_{C}}{\dot{m}_{C}}=\left[\left(\frac{\sigma \dot{Q}_{S T P}}{\dot{Q}_{S T P}}\right)^{2}+\sum_{i}\left(\frac{\# C_{i} \cdot \sigma\left[X_{i}\right]}{\sum_{i} \# C_{i}\left[X_{i}\right]}\right)^{2}\right]^{1 / 2} \\
& \frac{\sigma \dot{m}_{H}}{\dot{m}_{H}}=\left[\left(\frac{\sigma \dot{Q}_{S T P}}{\dot{Q}_{S T P}}\right)^{2}+\left(\frac{\# H_{i} \cdot \sigma\left[X_{i}\right]}{\# H_{i}\left[X_{i}\right]}\right)^{2}\right]^{1 / 2}
\end{aligned}
$$

The estimated uncertainties in the derived quantities are summarized in Table 3-3. 
Table 3-2. Species concentrations measured, molecular weights, and number of carbon and hydrogen atoms.

\begin{tabular}{|c|c|c|c|c|}
\hline $\mathrm{I}$ & Species & MW & $\# \mathrm{C}_{\mathrm{i}}$ 's & $\# \mathrm{H}_{\mathrm{i}}$ 's \\
\hline 1 & H2 (Hydrogen) & 2 & 0 & 2 \\
\hline 2 & C6H6 (Benzene) & 78 & 6 & 6 \\
\hline 3 & C3H8 (Propane) & 38 & 3 & 8 \\
\hline 4 & $\mathrm{C} 2 \mathrm{H} 2$ (Acetylene) & 26 & 2 & 2 \\
\hline 5 & C3H6 (Propylene) & 42 & 3 & 6 \\
\hline 6 & C4H10 (i-Butane) & 56 & 4 & 10 \\
\hline 7 & C3H4 (Propadiene) & 40 & 3 & 4 \\
\hline 8 & C4H10 (n-Butane) & 58 & 4 & 10 \\
\hline 9 & C4H8 (1-Butene) & 56 & 4 & 8 \\
\hline 10 & C4H8/C4H10 (i-Butylene/i-Butane) & 56 & 4 & 8 \\
\hline 11 & C4H8 (t-2-Butene) & 56 & 4 & 8 \\
\hline 12 & C4H8 (c-2-Butene) & 56 & 4 & 8 \\
\hline 13 & C4H6 (1,3-Butadiene) & 54 & 4 & 6 \\
\hline 14 & C5H12 (i-Pentane) & 72 & 5 & 12 \\
\hline 15 & C5H12 (n-Pentane) & 72 & 5 & 12 \\
\hline 16 & $\mathrm{CO} 2$ (Carbon dioxide) & 44 & 1 & 0 \\
\hline 17 & C2H4 (Ethylene) & 28 & 2 & 4 \\
\hline 18 & C2H6 (Ethane) & 30 & 2 & 6 \\
\hline 19 & Ar (Argon) & 40 & 0 & 0 \\
\hline 20 & N2 (Nitrogen) & 28 & 0 & 0 \\
\hline 21 & CH4 (Methane) & 16 & 1 & 4 \\
\hline 22 & $\mathrm{CO}$ (Carbon monoxide) & 28 & 1 & 0 \\
\hline
\end{tabular}


Table 3-3. Estimated uncertainties in derived quantities.

\begin{tabular}{lcc}
\hline \multicolumn{1}{c}{ Derived Quantity } & $\begin{array}{c}2 \sigma \text { Uncertainty Estimate } \\
\text { using turbine meter to } \\
\text { measure product } \\
\text { volumetric flow rate }\end{array}$ & $\begin{array}{c}2 \sigma \text { Uncertainty Estimate } \\
\text { using argon concentration } \\
\text { to estimate product } \\
\text { volumetric flow rate }\end{array}$ \\
\hline $\begin{array}{l}\text { Product Volumetric Flow Rate } \\
\dot{Q}_{S T P} \text { or } \dot{Q}_{S T P(A r)}\end{array}$ & $6.1 \%$ & $4.1 \%$ \\
Methane Yield & $7.4 \%$ & $5.8 \%$ \\
$y_{C H_{4}}$ & & $2.5 \%$ \\
Conversion Efficiency & $3.1 \%$ & $5.8 \%$ \\
CE & $($ maximum) & \\
Acetylene Yield & $7.4 \%$ & $5.7 \%$ \\
$y_{C_{2} H_{2}}$ & & \\
Product Stream Total Mass Flow Rate, & $7.3 \%$ & $5.7 \%$ \\
$\dot{m}_{t}$ & & $5.7 \%$ \\
Product Stream Carbon Mass Flow Rate, & $7.3 \%$ & \\
$\dot{m}_{C}$ & & \\
Product Stream Hydrogen Mass Flow Rate, & $7.3 \%$ & \\
$\dot{m}_{H}$ & & \\
\hline
\end{tabular}

Using the expressions given above and the primary measurements, the system mass balance uncertainty can be estimated. Independent direct measurement of the amount of solid carbon soot produced is an important component of the validation of the mass balance measurements. It is possible to weigh the downstream filter before and after a run; however, because soot deposits throughout the system, its rate of production is difficult to measure accurately. Two runs were performed to quantify the amount of soot produced. In these runs the entire system was carefully cleaned and the filter and carbon liner in the reactor section weighed. After each nominally 20 minute test run, the entire system was again disassembled and the solid carbon removed and weighed, along with the filter and reactor liner. The result of these runs are summarized in Table 3-4. The yield of solid carbon soot was found to be approximately $4.7 \%$ for a methane injection rate of $120.8 \mathrm{slm}$, and $1.9 \%$ for a methane injection rate of $98.5 \mathrm{slm}$. The power level in both runs was $60 \mathrm{~kW}$ deposited in the plasma gas.

The overall mass balance measurement performance for an example run is given in Table 3-5. The largest contributors to the uncertainty in the mass balance measurements are the downstream turbine meter and the gas chromatograph analysis of the product stream. Examination of the table indicates that the measured mass flow rates are within the uncertainty estimates given above. This same analysis was applied to each data point acquired. Only those data which demonstrate agreement of the mass balances within the estimated uncertainties were retained. This is the criteria that was used to disqualify the downstream meter turbine in those instances where it was difficult to determine if the measurement was degraded or not. In general, only $10 \%$ or less of the data was discarded, and repeat runs performed. In some instances a single test condition was repeated several times to quantify repeatability of the data. In all instances where this was done, the data all fell within the estimated uncertainty limits. 
Table 3-4. Rate of production of yield of solid carbon soot.

\begin{tabular}{ccccc}
\hline $\begin{array}{c}\text { Argon } \\
(\mathrm{slm})\end{array}$ & $\begin{array}{c}\text { Hydrogen } \\
(\mathrm{s} l \mathrm{~m})\end{array}$ & $\begin{array}{c}\text { Methane } \\
(\mathrm{s} / \mathrm{m})\end{array}$ & $\begin{array}{c}\text { Solid Carbon } \\
\text { Produced } \\
(\mathrm{g} / \mathrm{min})\end{array}$ & $\begin{array}{c}\text { Solid Carbon } \\
\text { Yield } \\
(\%)\end{array}$ \\
\hline 140 & 100 & 98.5 & 1.03 & 1.9 \\
140 & 100 & 120.8 & 3.02 & 4.7 \\
\hline
\end{tabular}

Table 3-5. Example of mass balance performance, $140 \mathrm{slm} \mathrm{Ar}, 100 \mathrm{slm} \mathrm{H}_{2}, 120.8 \mathrm{slm} \mathrm{CH}_{4}$.

\begin{tabular}{|c|c|c|c|c|c|}
\hline \multirow[b]{3}{*}{ Mass Component } & \multirow[b]{3}{*}{$\begin{array}{l}\text { Input } \\
\mathrm{g} / \mathrm{min}\end{array}$} & \multicolumn{4}{|c|}{ Product Stream } \\
\hline & & \multicolumn{2}{|c|}{ Turbine Meter } & \multicolumn{2}{|c|}{ Argon Flow Rate } \\
\hline & & $\begin{array}{c}\text { Measured } \\
\mathrm{g} / \mathrm{min}\end{array}$ & $\%$ Error & $\begin{array}{c}\text { Measured } \\
\mathrm{g} / \mathrm{min}\end{array}$ & $\%$ Error \\
\hline Total, $\dot{m}_{t}$ & 345.21 & 343.2 & 0.58 & 352.47 & -2.10 \\
\hline Carbon, $\dot{m}_{C}$ & 64.71 & 68.94 & -6.54 & 70.81 & -9.42 \\
\hline Hydrogen, $\dot{m}_{H}$ & 30.5 & 30.73 & -0.75 & 31.56 & -3.47 \\
\hline Argon, $\dot{m}_{A r}$ & 250.0 & 243.42 & 2.63 & 250 & 0 \\
\hline $\begin{array}{l}\text { Carbon Soot, } \\
\dot{m}_{C(S)}\end{array}$ & $\begin{array}{l}3.02 \\
\text { (measured) }\end{array}$ & $-4.23^{\mathrm{a}}$ & - & $-6.1^{\mathrm{a}}$ & - \\
\hline
\end{tabular}

a. Estimated from the difference of the carbon in the product stream and the input value. Since the uncertainty in the measured value is of the same order of magnitude as the difference, the uncertainty in the result is necessarily large. 


\section{RESULTS}

Two primary test series were conducted with the major difference between the two being the presence or absence of the converging-diverging quench nozzle. When the quench nozzle is installed, the downstream valve, V12, is wide open and the downstream pressure is determined by the capacity of the vacuum pump. The downstream pressure in this mode generally runs between 100 and 200 torr. In this configuration, the flow is choked in the converging-diverging nozzle throat and the reactor pressure is determined by the nozzle throat diameter, the reactor temperature, and the mass flow rate of the plasma and reactant gases. Under these conditions the reactor pressure generally ran between 600 and 800 torr for an upstream to downstream pressure ratio between 4 and 6 . The corresponding Mach number range is 1.6 to 1.8 . Assuming a reactor temperature of $2000{ }^{\circ} \mathrm{C}$, the aerodynamic quench rapidly lowers the temperature to $1100-1300{ }^{\circ} \mathrm{C}$. The measured thermal efficiency of the plasma torch was between 80 and $90 \%$ depending on the gas mixture and flow rates. The power to the plasma torch was adjusted to give a constant $60 \mathrm{~kW}$ deposited in the plasma gas. Since the torch voltage is essentially determined by the argon to hydrogen ratio, the power was adjusted by adjusting the current to obtain the desired $60 \mathrm{~kW}$ into the plasma. The injector ring, reactor section, and nozzle assembly, Figure 3-3, energy balances indicated that approximately $14.6 \mathrm{~kW}$ were lost in these components to the cooling water. The partitioning of this energy loss is illustrated in Figure 4-1.

The result is that approximately $45 \mathrm{~kW}$ is available for conversion of natural gas to acetylene. By careful system redesign, which includes placement of the injector function inside the torch body and optimization (shortening) of reactor length, these losses can probably be reduced by $70 \%$ or more. Figure 4-2 contains a plot of the theoretical maximum amount of methane that can be converted to acetylene in the current configuration under nominal operating conditions. Nominal operating conditions are defined as $160 \mathrm{slm} \mathrm{Ar}, 100 \mathrm{slm} \mathrm{H}_{2}$ for the plasma torch gas and $60 \mathrm{~kW}$ deposited in the plasma. The target reactor temperature is $2000{ }^{\circ} \mathrm{C}$. Under the nominal conditions the maximum theoretical amount of methane that can be converted to acetylene is approximately $145 \mathrm{slm}$.

\subsection{Results with Converging-Diverging Nozzle}

Conversion efficiency as a function of the rate of methane injection is plotted in Figure 4-3. In developing this data set the power deposited in the plasma was maintained constant at $60 \mathrm{~kW}$ and the plasma gas flow rates were constant at $160 \mathrm{slm} \mathrm{Ar}$ and $100 \mathrm{slm} \mathrm{H}_{2}$. The measured reactor pressure was relatively constant, varying between approximately 670 and 730 torr, depending on the rate of methane injection. Methane conversion is essentially complete, that is a conversion efficiency of $100 \%$, at methane feed rates up to about $100 \mathrm{slm}$. At feed rates above $100 \mathrm{slm}$ the conversion efficiency starts to decline and dips below approximately $95 \%$ at a feed rate of around $120 \mathrm{slm}$. The estimated bulk gas temperature in the reactor and corresponding residence time in the reactor is plotted in Figure 4-4. This estimate is obtained from the measured system energy balance, the plasma gas and methane flow rates, and the assumption of $100 \%$ acetylene yield. The target temperature of approximately $2000{ }^{\circ} \mathrm{C}$ is reached at a methane flow rate of approximately $145 \mathrm{slm}$. For methane injection rates less than $145 \mathrm{slm}$ the estimated reactor temperature is greater than $2000^{\circ} \mathrm{C}$. If the reactor temperature is uniform, which it is

\begin{tabular}{|l|l|l|l|}
\hline Torch & Injector & Reactor & Nozzle \\
$+60 \mathrm{~kW}$ into plasma & $-7.3 \mathrm{~kW}$ to cooling water & $-3.9 \mathrm{~kW}$ to cooling water & $-3.4 \mathrm{~kW}$ to cooling water \\
\hline
\end{tabular}

Figure 4-1. Partitioning of energy loss to cooling water. 


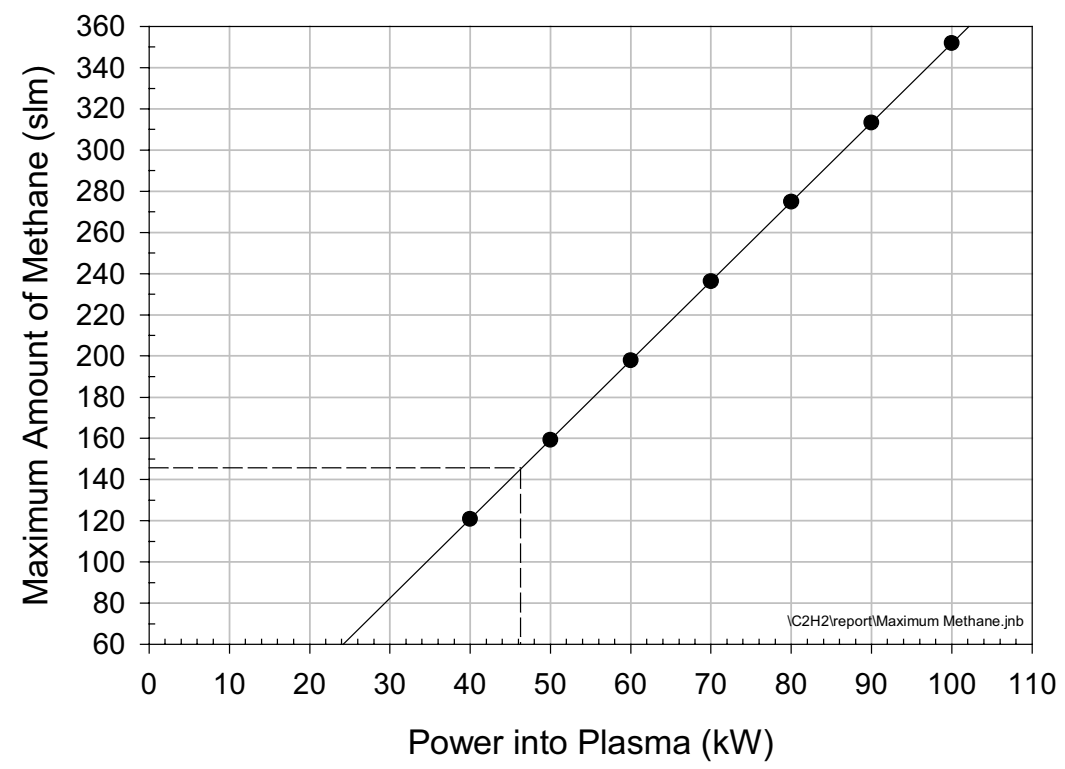

Figure 4-2. The theoretical maximum amount of methane that can be processed in current system, $160 \mathrm{slm}$ Ar, $100 \mathrm{slm}_{2}$.

not, and if the process follows the equilibrium diagram of Figure 4-2, it is expected that for temperatures much below $2000{ }^{\circ} \mathrm{C}$ (methane feed rates greater that about $145 \mathrm{slm}$ ) that the conversion efficiency will start to decline. An alternative representation of this appeared in Figure 4-2 where the maximum amount of methane that it is theoretically possible to process is plotted as a function of energy (power) available. For the nominal operating condition of $60 \mathrm{~kW}$ into the plasma gas minus the 15 or so $\mathrm{kW}$ that is lost in the injector, reactor and nozzle assembly for a net of about $45 \mathrm{~kW}$, the maximum amount of methane that can be processed is approximately $145 \mathrm{slm}$. For injection rates in excess of $145 \mathrm{slm}$ there is not enough energy available to dissociate and convert the injected methane to acetylene with $100 \%$ efficiency and result in a product stream temperature of $2000{ }^{\circ} \mathrm{C}$. The presence of the inevitable cold boundary layers in the injection ring and reactor also result in some gas that can pass through the reactor without being dissociated. At the lower flow rates and corresponding higher temperatures the methane is almost completely converted and the conversion efficiency approaches $100 \%$. The conversion efficiency is observed to decline at $120 \mathrm{slm}$, somewhat below the anticipated value of $145 \mathrm{slm}$. This may be due to the presence of cold boundary layer flow, or due to inadequate residence time for dissociation. Inspection of the residence time plot in Figure 4-4, shows that the residence time in the reactor is relatively constant and independent of methane injection rate. The increase in mass flow rate and anticipated velocity increase with increased methane injection is offset by the cooling of the gas mixture that also occurs with increased methane injection rate.

The possible influence of residence time on conversion efficiency was evaluated by replacing the converging-diverging nozzle with a straight, constant diameter section that matched the inside diameter of the downstream piping. By removing the converging-diverging nozzle the reactor pressure could be controlled independently of the flow rates. When the converging-diverging nozzle is installed the flow is choked (reaches sonic velocity) in the nozzle throat. Under this condition the reactor pressure is independent of the downstream pressure and is determined solely by the mass flow rate and temperature. With the converging-diverging nozzle removed the reactor pressure is controlled by the position of a 


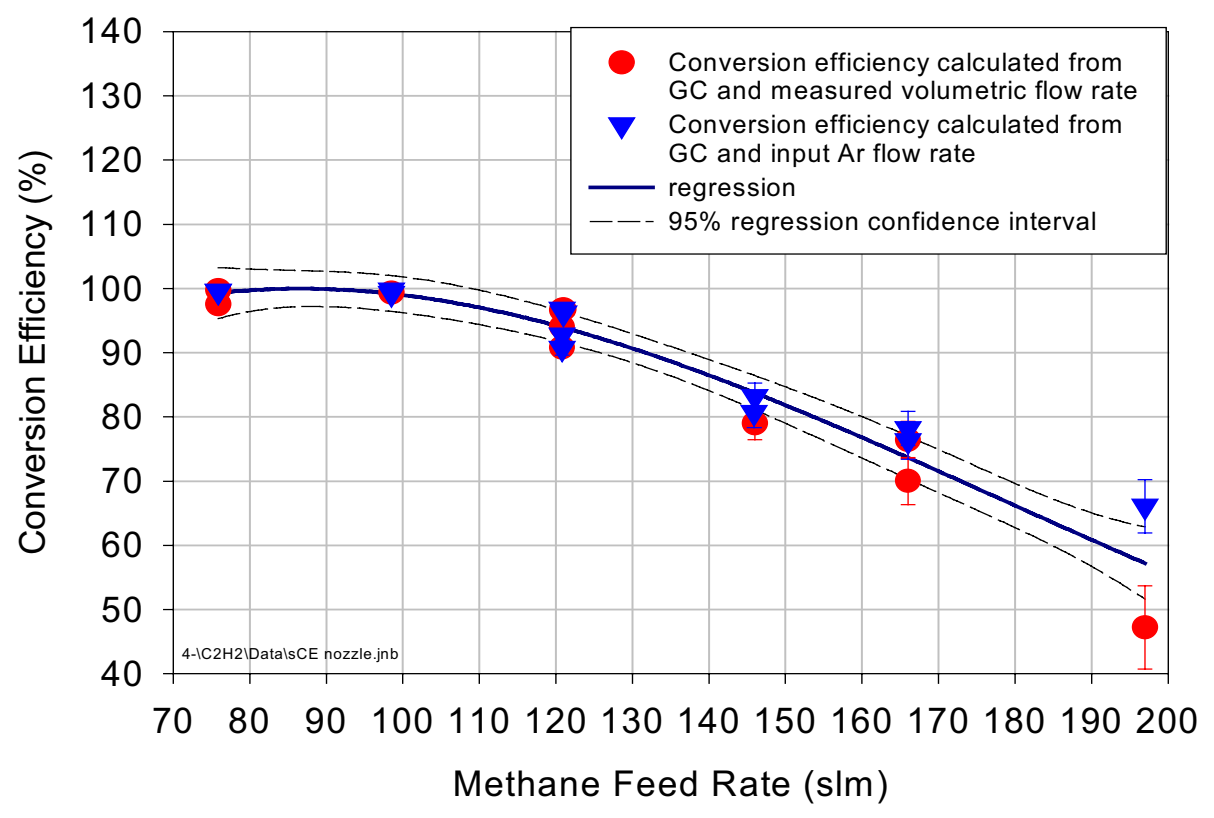

Figure 4-3. Conversion efficiency as a function of methane feed rate, plasma power is constant at $60 \mathrm{~kW}$, and plasma gas flow rates are constant at $160 \mathrm{slm} \mathrm{Ar}$ and $100 \mathrm{slm} \mathrm{\textrm {H } _ { 2 }}$.

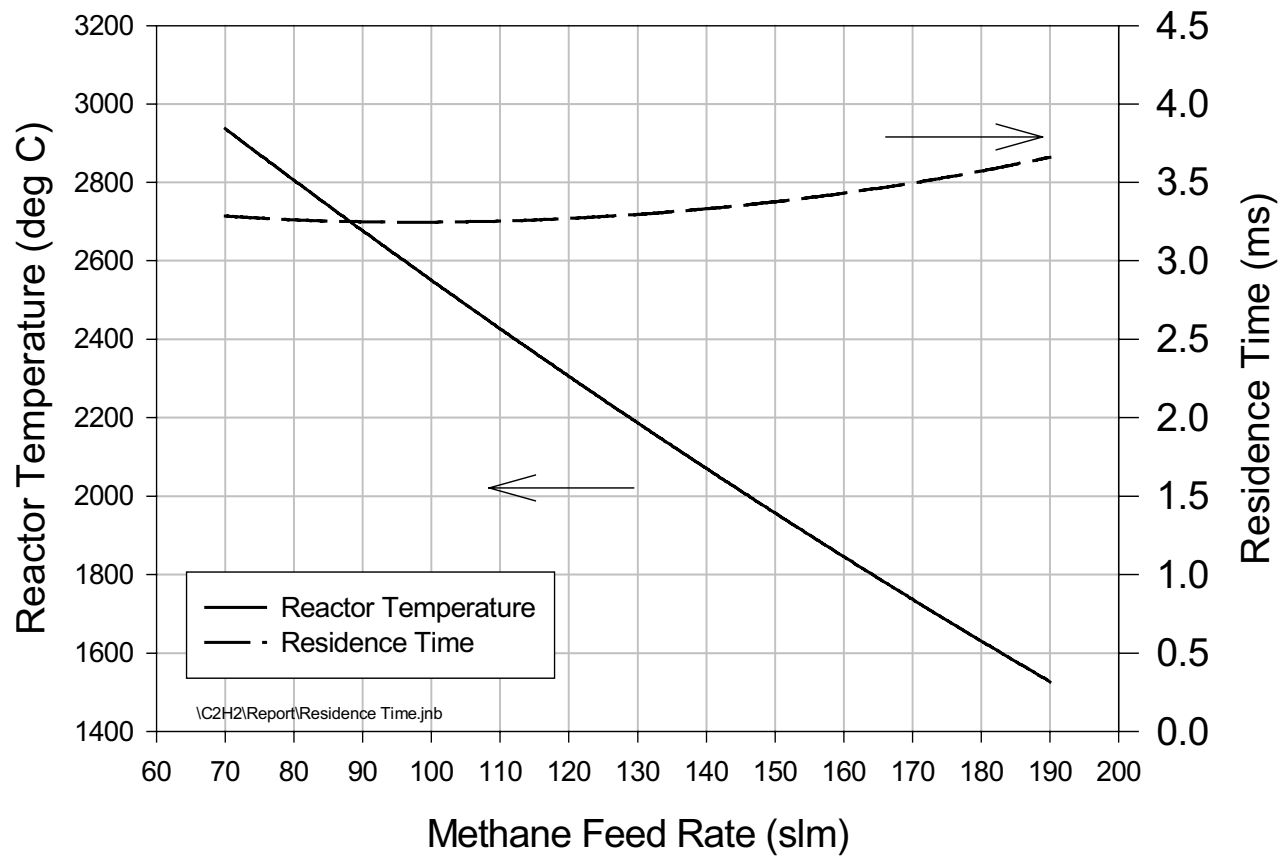

Figure 4-4. Estimated reactor temperature and reactor residence time as a function of methane injection rate. 
downstream valve. Decreasing the reactor pressure increases the velocity in the reactor and decreases residence time. For this series of tests the pressure was varied from 300 to 700 torr, decreasing the residence time in the reactor by a factor of 2.3 , or from about $3.25 \mathrm{~ms}$ to $1.4 \mathrm{~ms}$. A slight decrease in conversion efficiency of about 2 percentage points, is observed at the lower pressures, Figure 4-5. While this suggests a slight dependence on residence time it is not enough to account for the decrease in conversion efficiency observed in Figure 4-3. This suggests that the presence of cold boundary layers is in fact mostly responsible for the observed decrease. The residence time in the reactor is sufficient for dissociation of the methane, and as we will show next, also sufficient for the formation of acetylene.

Acetylene yield as a function of methane injection rate appears in Figure 4-6. The trends observed in the yield data are similar to those observed in the plot of conversion efficiency, Figure 4-3. The acetylene yield is approximately $95 \%$ for methane injection rates less than about $100 \mathrm{slm}$. Further increases in methane injection rate result in a decrease of yield. At an injection rate of $145 \mathrm{slm}$, the theoretical maximum feed rate that can be processed with conversion efficiency and yield approaching $100 \%$, the measured yield has dropped to $75 \%$. In Figure 4-7, the measured yield has been normalized to account for the measured decrease in conversion efficiency. This normalization is simply

$$
\text { yield }_{\text {normalized }}=\frac{\text { yield }}{\text { conversion efficiency }}
$$

The normalized yield is a measure of selectivity for conversion to acetylene. As illustrated in Figure 4-7, this normalization accounts for a significant portion of the observed decrease in acetylene yield. Improving the conversion efficiency will flatten the yield curve significantly. This suggests that minimization of the cold boundary layers through improved thermal design can result in an improvement in overall system performance and that the intrinsic acetylene yield is high over a wide range at reactant flow rates (reactor temperature).

The decrease in the measured yield that is not accounted for by the decrease in conversion efficiency is due to the formation of other carbon containing species. These include other hydrocarbons and soot. Figures 4-8 and 4-9 contain plots of the carbon basis yield of the other hydrocarbon species observed as a function of methane injection rate. Yield is given as a percentage of carbon introduced into the system as methane. The figures are identical except for scale and the absence of methane in Figure 4-9. In Figure 4-8 the decrease in conversion efficiency with increased methane injection rate is evident in the increase in methane yield. Figure 4-9 is the same data plotted on an expanded scale. The observed decrease in the normalized yield is due to an increase in the yield of other carbon containing species. The species represented on the plot are the only ones observed by the gas chromatograph. Interestingly enough, after an initial increase in the yield of olefins plus the $\mathrm{C}_{6}$ and heavier $(\mathrm{C} 5=/ \mathrm{C} 6+)$ hydrocarbons the relative amount decreases slightly at higher methane injection rates. These relatively heavy hydrocarbons were subsequently identified as almost entirely benzene by GCMS analysis. The other carbon containing species observed, ethylene, propadiene, and t-2-butene steadily increase as the rate of methane injection increases. The dependence of conversion, yield, and the yield of other hydrocarbon species on the relative amounts of $\mathrm{Ar}$ and $\mathrm{H}_{2}$ ratio was examined by decreasing the $\mathrm{Ar}$ to $\mathrm{H}_{2}$ ratio by a factor of two. There was no noticeable effect on the conversion efficiency or on the composition of the product stream. Because the product stream is always characterized by an abundance of $\mathrm{H}_{2}$, the Ar present appears to have little or no effect on the kinetics and does not shift the equilibrium of the product stream.

In addition to the tests utilizing methane as the reactant gas, a limited number of runs were performed using pipeline natural gas. The observed conversion efficiencies, acetylene yields and the yields of other hydrocarbons were identical to the prior results using pure methane as the feedstock. The analyses of the natural gas and product streams appear in Table 4-1. 


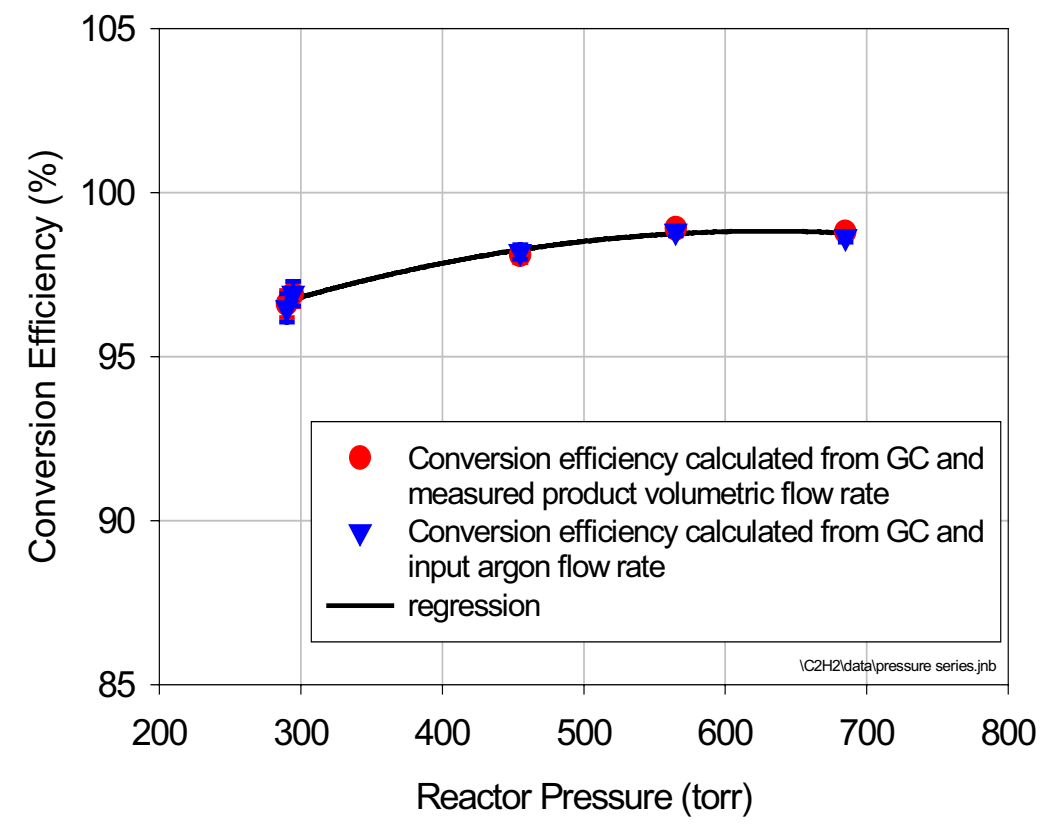

Figure 4-5. Methane conversion efficiency as a function of reactor pressure.

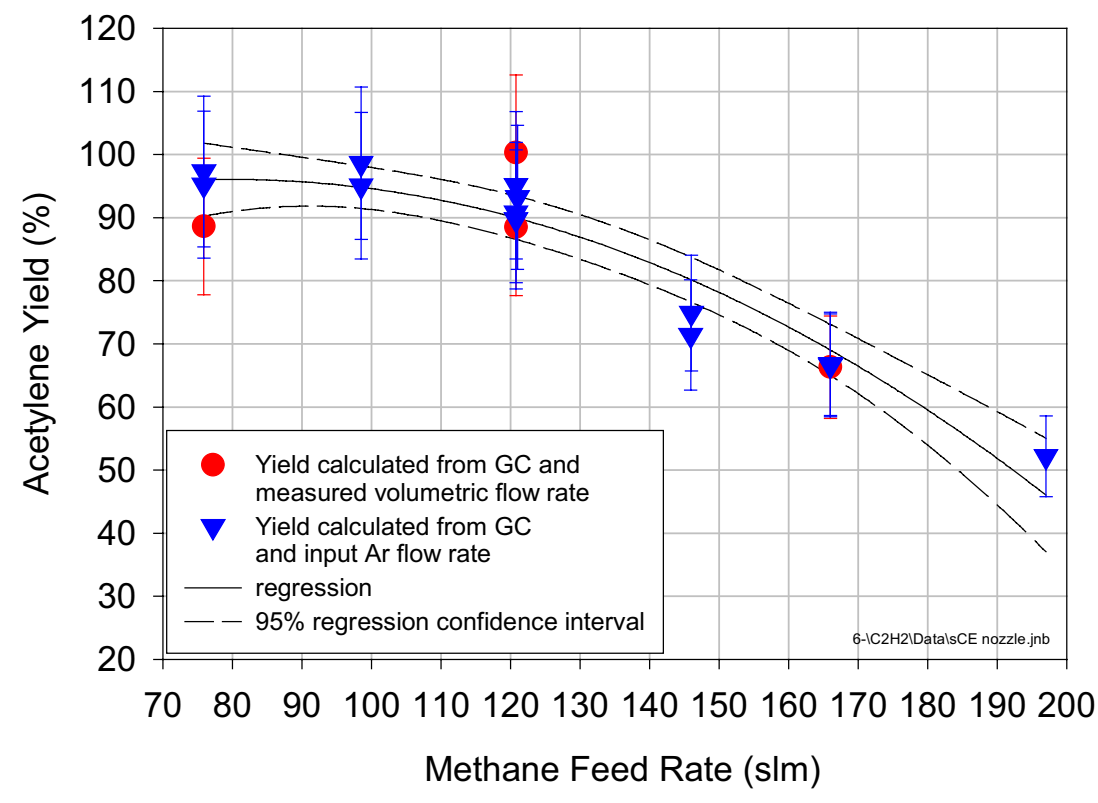

Figure 4-6. Acetylene yield as a function of methane injection rate. 


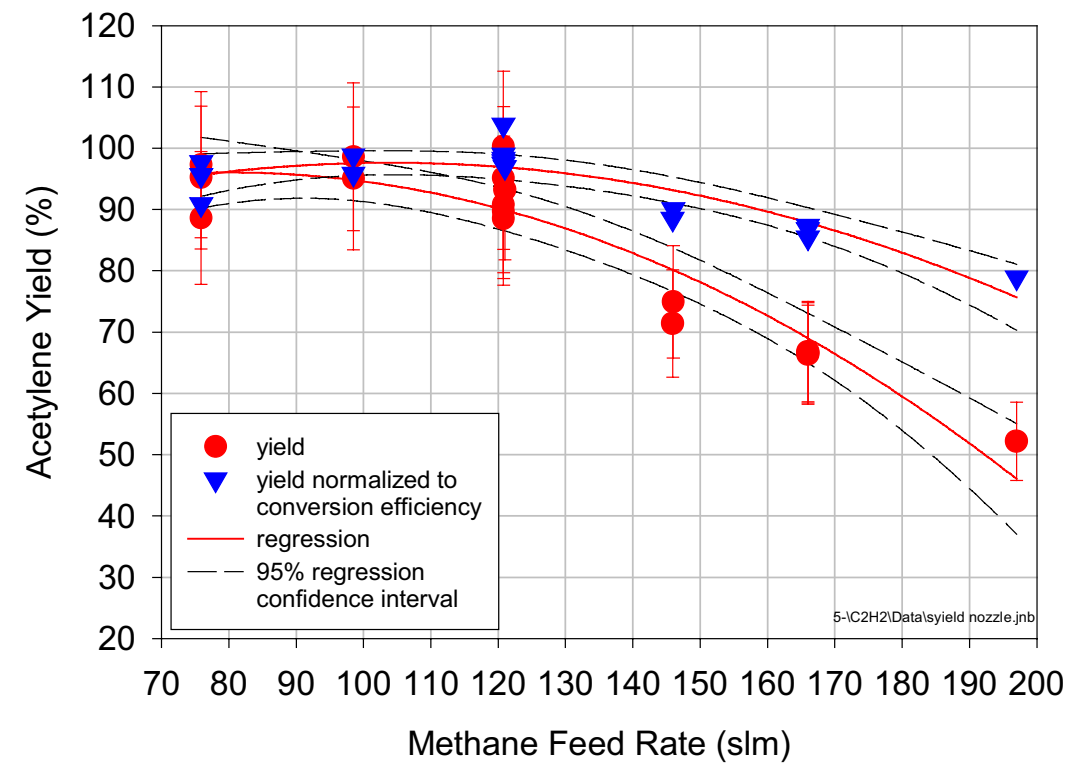

Figure 4-7. Normalized acetylene yield.

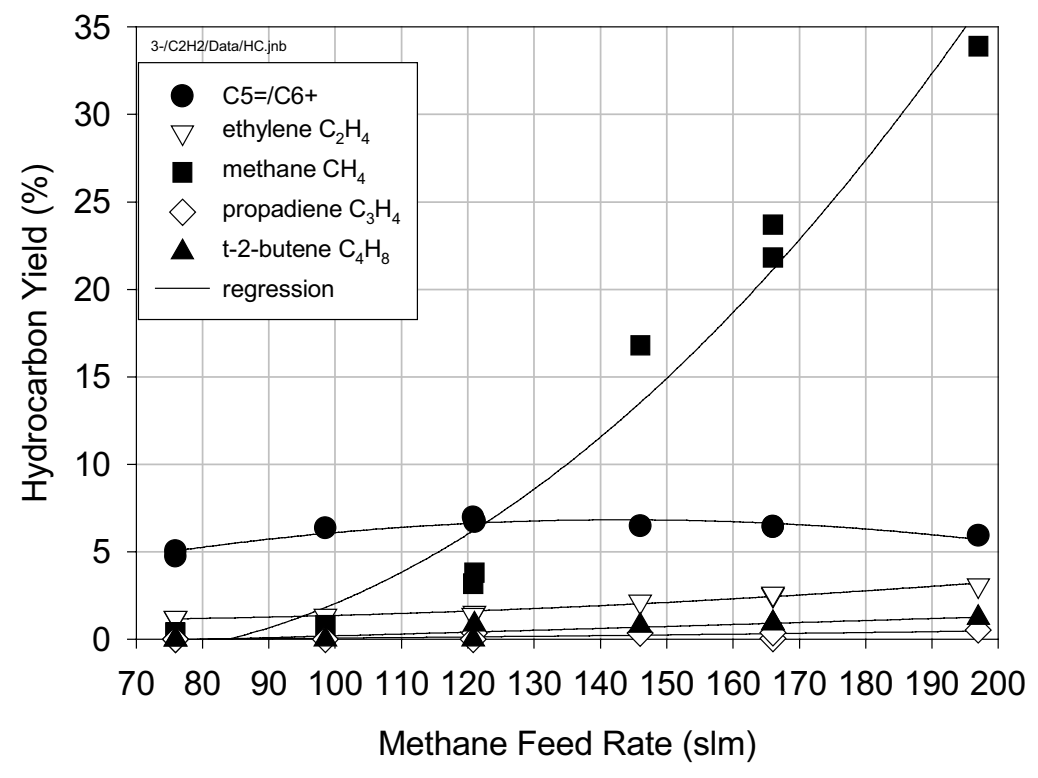

Figure 4-8. Yield of all other observed hydrocarbons. 


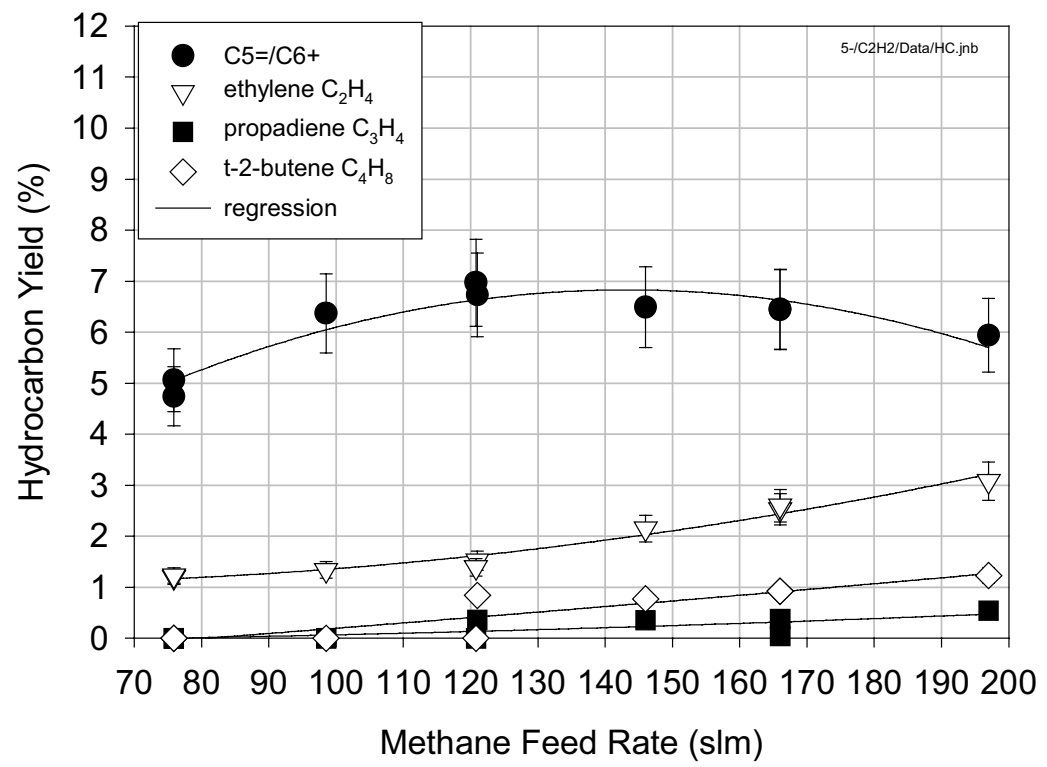

Figure 4-9. Yield of all other observed hydrocarbons less methane.

Table 4-1. Gas chromatograph analysis of natural gas reactant and product stream in mole percent, $60 \mathrm{~kW}$ plasma power, $140 \mathrm{slm} \mathrm{Ar}, 100 \mathrm{slm} \mathrm{H}_{2}$, and $98.5 \mathrm{slm}$ natural gas.

\begin{tabular}{|c|c|c|c|c|c|c|c|c|c|c|c|c|c|c|}
\hline & $\mathrm{H}_{2}$ & $\mathrm{C} 5=/ \mathrm{C}_{6}{ }^{+}$ & $\begin{array}{c}\mathrm{C}_{3} \mathrm{H}_{8} \\
\text { Propane }\end{array}$ & $\begin{array}{c}\mathrm{C}_{2} \mathrm{H}_{2} \\
\text { Acetylene }\end{array}$ & $\begin{array}{c}\text { i-Butane } \\
\mathrm{C}_{4} \mathrm{H}_{10}\end{array}$ & $\begin{array}{c}\text { n-Butane } \\
\mathrm{C}_{4} \mathrm{H}_{10}\end{array}$ & $\mathrm{CO}_{2}$ & $\begin{array}{c}\mathrm{C}_{2} \mathrm{H}_{4} \\
\text { Ethylene }\end{array}$ & $\begin{array}{c}\mathrm{C}_{2} \mathrm{H}_{6} \\
\text { Ethane }\end{array}$ & $\mathrm{Ar}$ & $\mathrm{N}_{2}$ & $\begin{array}{c}\mathrm{CH}_{4} \\
\text { Methane }\end{array}$ & $\mathrm{CO}$ & $\begin{array}{c}\text { Solid } \\
\text { Carbon } \\
\text { Yield }\end{array}$ \\
\hline $\begin{array}{l}\text { Natural } \\
\text { Gas }\end{array}$ & 0 & 0.04 & 0.74 & $-0-$ & 0.10 & 0.11 & 0.51 & 0 & 3.79 & 0.04 & 1.18 & 93.47 & 0 & - \\
\hline $\begin{array}{l}\text { Product } \\
\text { Stream }\end{array}$ & 53.47 & .34 & 0 & 11.8 & 0 & 0 & 0 & .182 & 0 & 33.3 & 0.44 & 0.21 & 0.247 & $3.2 \%$ \\
\hline
\end{tabular}

The results are virtually identical to the pure methane runs with the exception of the $\mathrm{N}_{2}$, which is essentially inert, and the conversion of the $\mathrm{CO}_{2}$ to $\mathrm{CO}$. In a carbon rich system the $\mathrm{CO}-\mathrm{CO}_{2}$ equilibrium tends toward $\mathrm{CO}$ at relatively modest temperatures on the order of $1000{ }^{\circ} \mathrm{C}$.

\subsection{Results Without Converging-Diverging Nozzle}

The conversion efficiency ( $\sim 100 \%$ vs. $70 \%$ ), yield, and selectivity ( $95 \%$ vs. $51 \%$ ) of the process demonstrated appear to be somewhat superior to the original Huels process. The Huels product stream analysis as well as the laboratory scale results are summarized in Table 4-2. This may be due to better mixing, temperature uniformity, or more rapid quenching. To assess the effect of rapid aerodynamic quenching a series of tests, identical to those reported in section 4.1 were conducted, but without the converging diverging nozzle. In these tests the system pressure was maintained at between 700 and 900 torr, approximately the same as the reactor pressure in the first test series. Conversion efficiency, yield, and nomalized yield results are summarized in Figures 4-10-4-12. The yield of other hydrocarbon species is summarized in Figure 4-13. 
The yield and conversion efficiency results without the converging-diverging nozzle and supersonic aerodynamic quench are virtually identical to the earlier results developed with the nozzle present. There appears to be some minor improvement in yield at the higher methane injection rates when the nozzle is present, but the deviations are within the uncertainty estimate and the error bars significantly overlap. Examination of yields of other hydrocarbons, Figure 4-13, indicate a statistically significant difference in the yield of ethylene between the results with the nozzle removed and with the nozzle in place, Figure 4-9. Apparently the high quench rates afforded by the nozzle have the effect of suppressing the formation of ethylene, cutting the yield of ethylene by approximately $30 \%$. The exact mechanism of ethylene formation is as yet undefined; however, it is likely that the kinetics and population of the $\mathrm{CH}_{2}$ radical play an important role.

With the converging-diverging nozzle removed, the reactor pressure can be independently controlled with valve V12. This configuration allows investigation of the effect of pressure on yield. It was demonstrated earlier, Figure 4-5, that pressure and residence time have only a small effect on conversion efficiency. Measured acetylene yield is plotted as a function of reactor pressure in Figure 4-14. The power is constant at $60 \mathrm{~kW}$ into the gas and the flow rates are maintained at $160 \mathrm{slm} \mathrm{Ar}$, $100 \mathrm{slm} \mathrm{H}_{2}$, and $98.5 \mathrm{slm} \mathrm{CH}_{4}$. There appears to be a slight decrease in acetylene yield with increasing pressure although the effect is not large. The decrease in yield is accompanied by a slight decrease in benzene yield and an increase in ethylene yield, Figure 4-15. In general, pressure changes in the range of 300-700 torr do not have a large effect. 


\begin{tabular}{|c|c|c|c|c|c|}
\hline & 章 & ' & $\frac{\stackrel{0}{0}^{\circ}}{i}$ & 1 & ণे \\
\hline & $z^{N}$ & $\ddot{v}$ & $\hat{\sim}$ & $\stackrel{\infty}{=}$ & $\stackrel{8}{8}$ \\
\hline & 0 & ' & 0 & ' & ڤn \\
\hline & $I^{2}$ & ' & ণ். & ' & $\begin{array}{l}\vec{f} \\
\dot{n} \\
\tilde{n}\end{array}$ \\
\hline 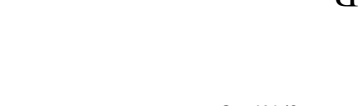 & $\underbrace{0}_{0}$ & ' & $\ddot{0}$ & $\stackrel{1}{0}$ & $\stackrel{+}{m}$ \\
\hline & $\overrightarrow{\vec{J}^{+}} 。$ & $\stackrel{+}{0}$ & 1 & $\overline{0}$ & ' \\
\hline วuॄฺng-! & $\overrightarrow{\bar{U}^{+}} 。$ & ' & $\stackrel{0}{0}$ & $\frac{0}{0}$ & ' \\
\hline aurdo. $I_{\mathbf{d}}$ & $\underset{0}{\stackrel{\infty}{0}}$ & $n$ & $\hat{0}$ & $\frac{J}{0}$ & ' \\
\hline วนеч1 & $\underset{\widetilde{U}}{\mathbb{I}}$ & $\stackrel{\forall}{-}$ & 盛 & $\frac{a}{r}$ & ' \\
\hline әиечрәК & ت्ञ & ñ. & $\ddot{0}$ & fं & $\bar{\jmath}$ \\
\hline әиә[Кчાн & $\underset{U^{N}}{I^{*}}$ & ' & $\hat{0}$ & ' & ' \\
\hline & $\underbrace{+}_{U^{+}}$ & ' & $\overrightarrow{0}$ & ' & ' \\
\hline 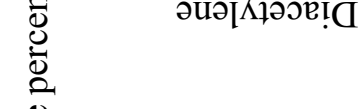 & $\underset{U^{*}}{I^{2}}$ & ' & $\ddot{0}$ & ' & ' \\
\hline әนӘIIV & $\underset{S^{T}}{I^{+}}$ & ' & $\stackrel{+}{0}$ & ' & ' \\
\hline 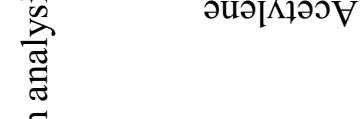 & $\underset{S^{N}}{I^{\prime}}$ & 1 & $\stackrel{n}{ \pm}$ & 1 & $\stackrel{\infty}{=}$ \\
\hline 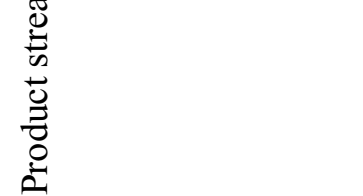 & & 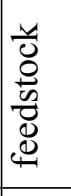 & 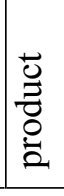 & 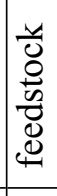 & 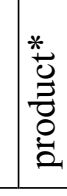 \\
\hline $\begin{array}{l}\underset{j}{J} \\
\frac{0}{0} \\
\frac{0}{0}\end{array}$ & & \multicolumn{2}{|c|}{ 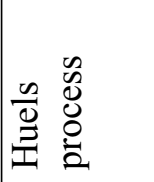 } & \multicolumn{2}{|c|}{ 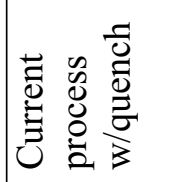 } \\
\hline
\end{tabular}




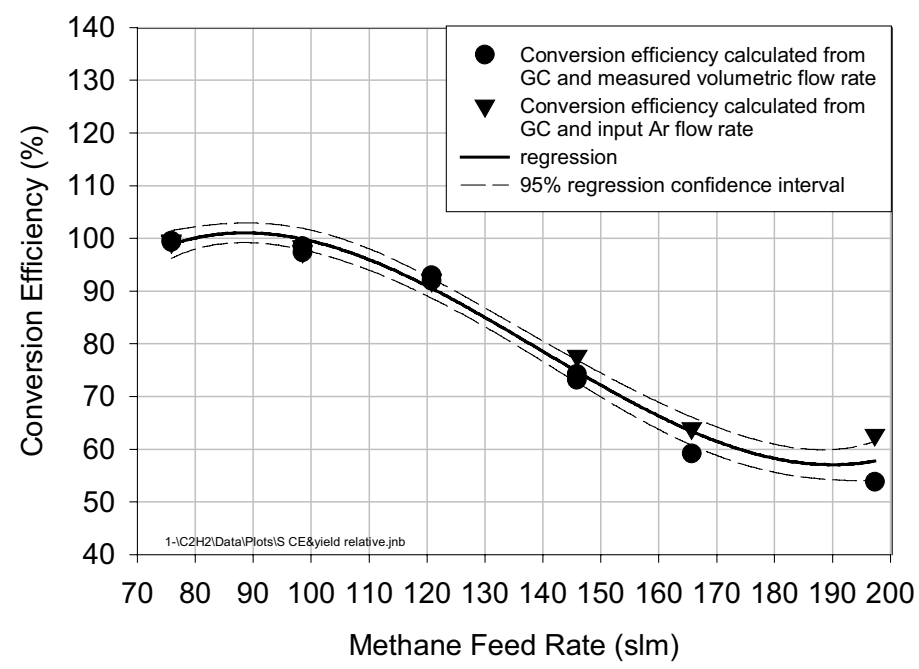

Figure 4-10. Conversion efficiency as a function of methane feed rate, plasma power is constant at $60 \mathrm{~kW}$ and plasma gas flow rates are constant at $160 \mathrm{slm} \mathrm{Ar}$ and $100 \mathrm{slm} \mathrm{H}_{2}$. The converging-diverging nozzle has been removed.

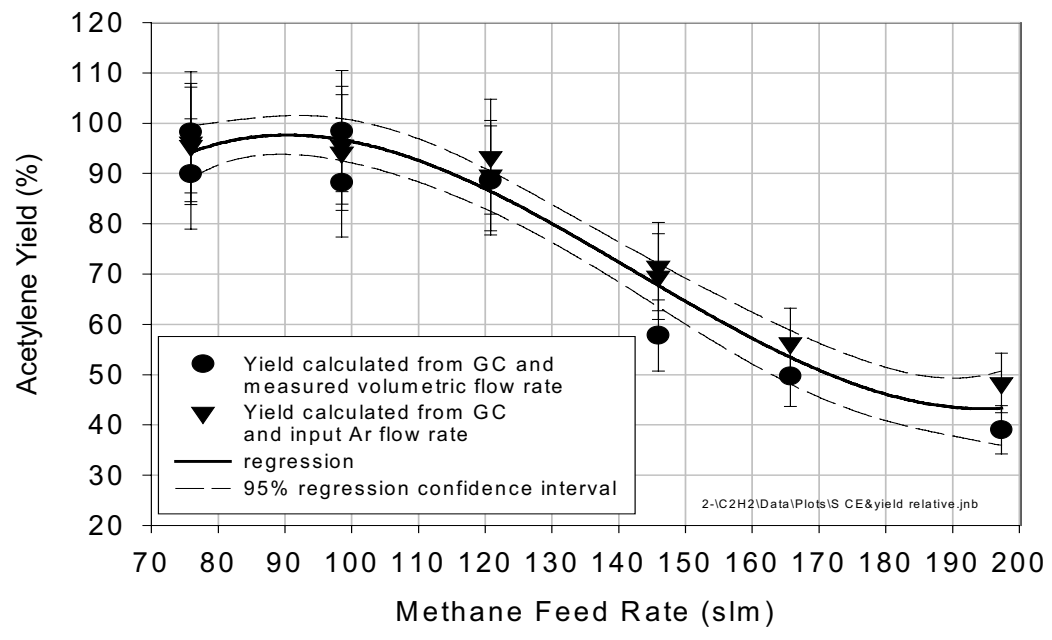

Figure 4-11. Acetylene yield as a funciton of methane injection rate. The converging-diverging nozzle has been removed. 


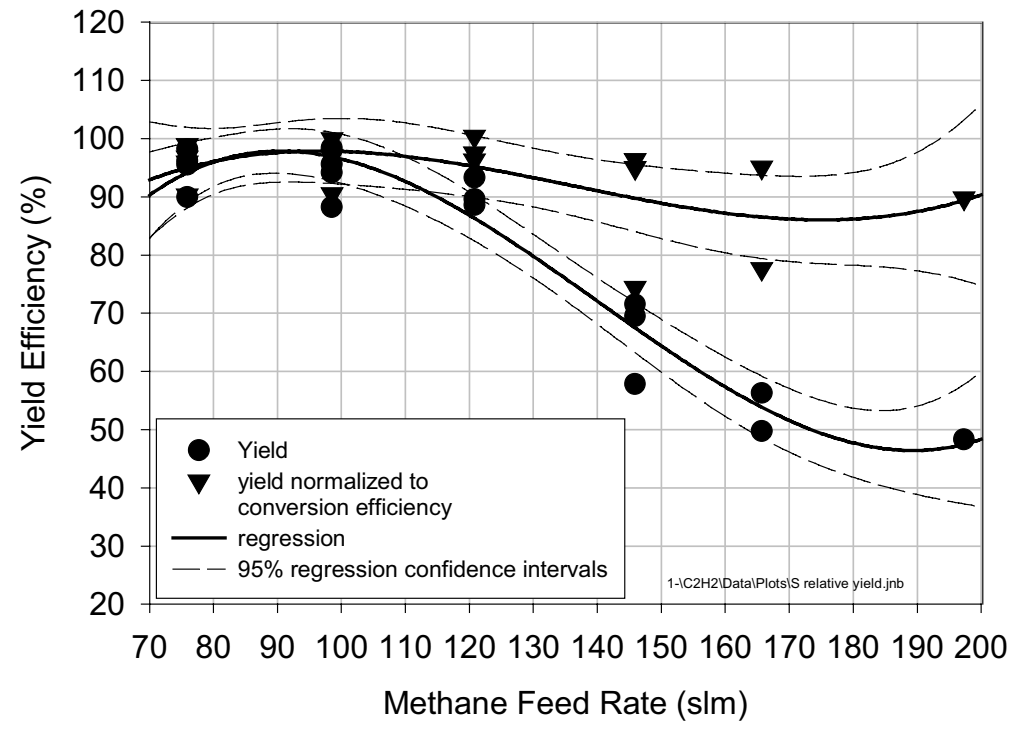

Figure 4-12. Normalized acetylene yield.

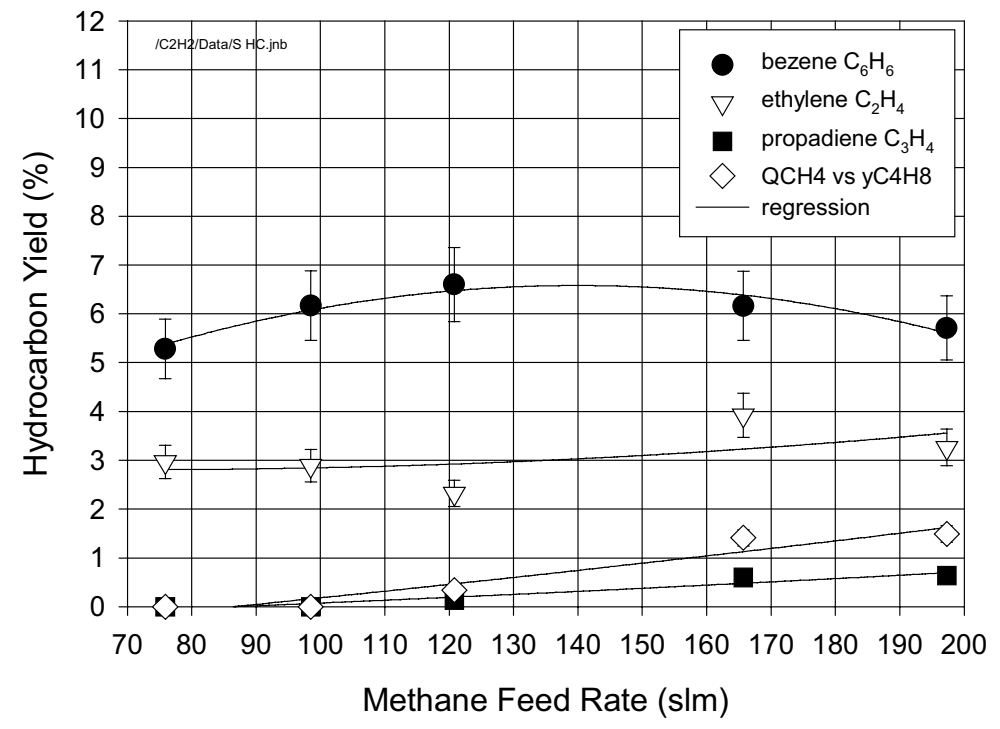

Figure 4-13. Yield of all other observed hydrocarbons, less methane. The converging-diverging nozzle has been removed. 


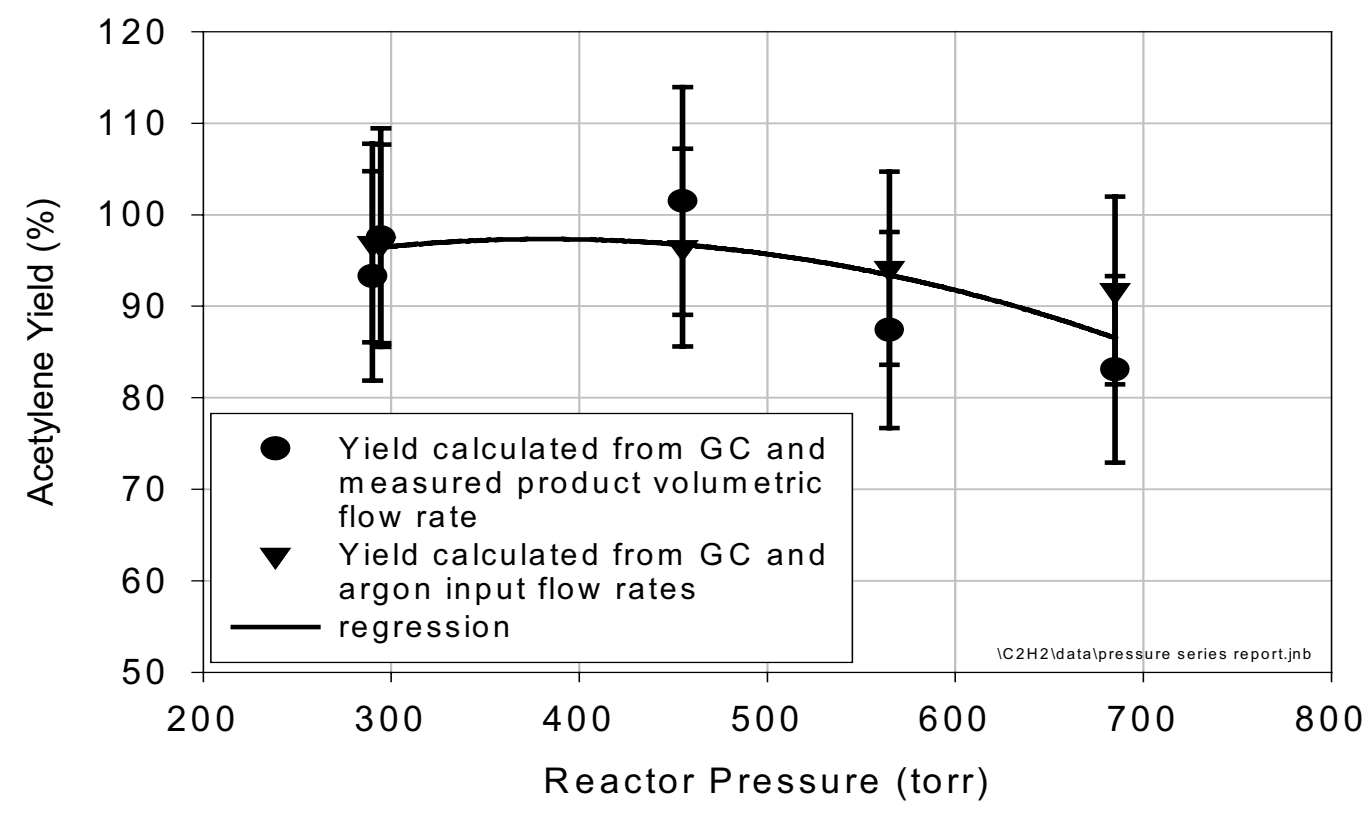

Figure 4-14. Acetylene yield as a function of pressure, converging-diverging nozzle removed, $160 \mathrm{slm}$

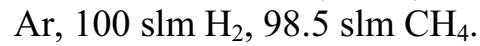

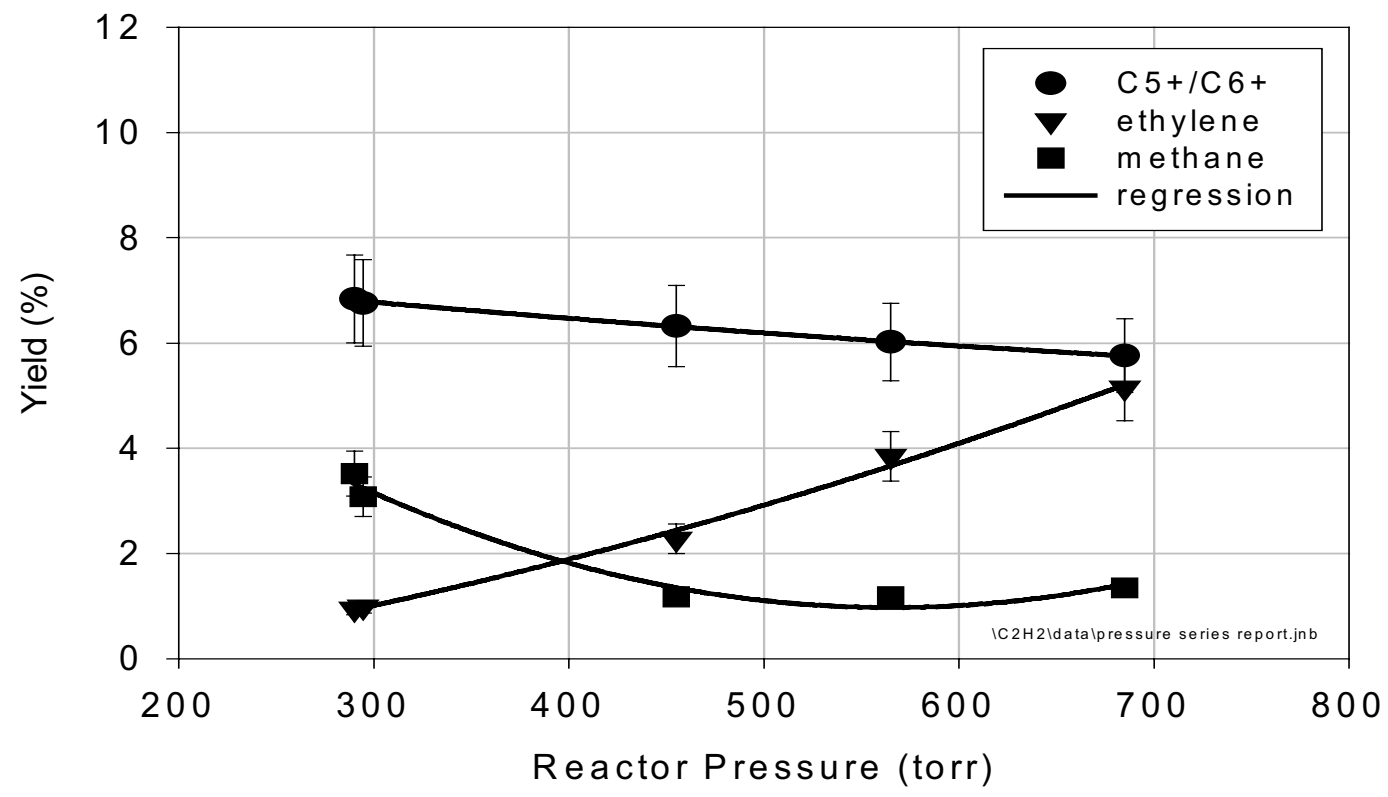

Figure 4-15. Hydrocarbon yield as a function of reactor pressure. 


\section{SUMMARY AND DISCUSSION}

In this section we will briefly summarize the pertinent results and compare to some of the available prior results. In particular, conversion efficiency, acetylene yield and yield of other hydrocarbons will be addressed along with the specific energy consumption.

\subsection{Product Yield}

The measured conversion efficiency and acetylene yield in the laboratory reactor system described here are in general somewhat better than reported in the literature; conversion efficiencies approach $100 \%$ and yields in the $90-95 \%$ range with $2-4 \%$ soot produced have been demonstrated. This appears to be somewhat of an improvement over the Huels process $\left(\mathrm{CE}=70.5 \%\right.$ and $\mathrm{YC}_{2} \mathrm{H}_{2}=51.4 \%, 2.7 \%$ carbon soot) and the DuPont process ( $\mathrm{CE}$ - not reported, $\mathrm{YC}_{2} \mathrm{H}_{2}=70 \%$ ). The process reported here also appears to have somewhat better specificity for acetylene. The improvement in conversion efficiency, yield and specificity are due primarily to improved injector design and mixing (a better "stirred" reactor) and minimization of temperature gradients and cold boundary layers. The rate of cooling by wall heat transfer appears to be sufficient to quench the product stream and prevent further decomposition of acetylene into soot or further reaction leading to heavier hydrocarbon products. Significantly increasing the quench rate by rapidly expanding the product stream through a converging-diverging nozzle leads to only marginal improvement in the composition of the product stream, primarily the reduction of the yield of ethylene.

\subsection{Specific Energy Consumption}

The specific amount of energy consumed $(\mathrm{kW}-\mathrm{hr})$ per amount $(\mathrm{kg})$ of acetylene produced ultimately determines the economics of the process. The Huels process reportedly consumed $12.1 \mathrm{~kW}-$ $\mathrm{hr} / \mathrm{kg}-\mathrm{C}_{2} \mathrm{H}_{2}$ produced. The DuPont process specific energy consumption was estimated, though not measured, to be $8.8 \mathrm{~kW}-\mathrm{hr} / \mathrm{kg}-\mathrm{C}_{2} \mathrm{H}_{2}$ produced. This later value compares favorably with the theoretical minimum value of approximately $7.9 \mathrm{~kW}-\mathrm{hr} / \mathrm{kg}-\mathrm{C}_{2} \mathrm{H}_{2}$ for a product stream at $2000{ }^{\circ} \mathrm{C}, 100 \%$ conversion efficiency and yield and no electrical or thermal losses. The measured specific energy consumption for the laboratory scale process examined in this study is plotted in Figure 5-1. The minimum measured specific energy consumption is approximately $16 \mathrm{~kW}-\mathrm{hr} / \mathrm{kg}-\mathrm{C}_{2} \mathrm{H}_{2}$ produced. It is estimated that this could be improved to a value of around $13 \mathrm{~kW}-\mathrm{hr} / \mathrm{kg}-\mathrm{C}_{2} \mathrm{H}_{2}$ by improved thermal design. This includes moving the injection into the torch body thus avoiding the thermal losses in the injector ring and reducing the thermal losses in the reactor section. Process heat recovery might further reduce the specific energy consumption by another $20 \%$ or so to around the $10 \mathrm{~kW}-\mathrm{hr} / \mathrm{kg}-\mathrm{C}_{2} \mathrm{H}_{2}$ range. These numbers compare favorably with the specific energy consumption reported for the Huels and DuPont processes while demonstrating improved conversion efficiency and yield. 


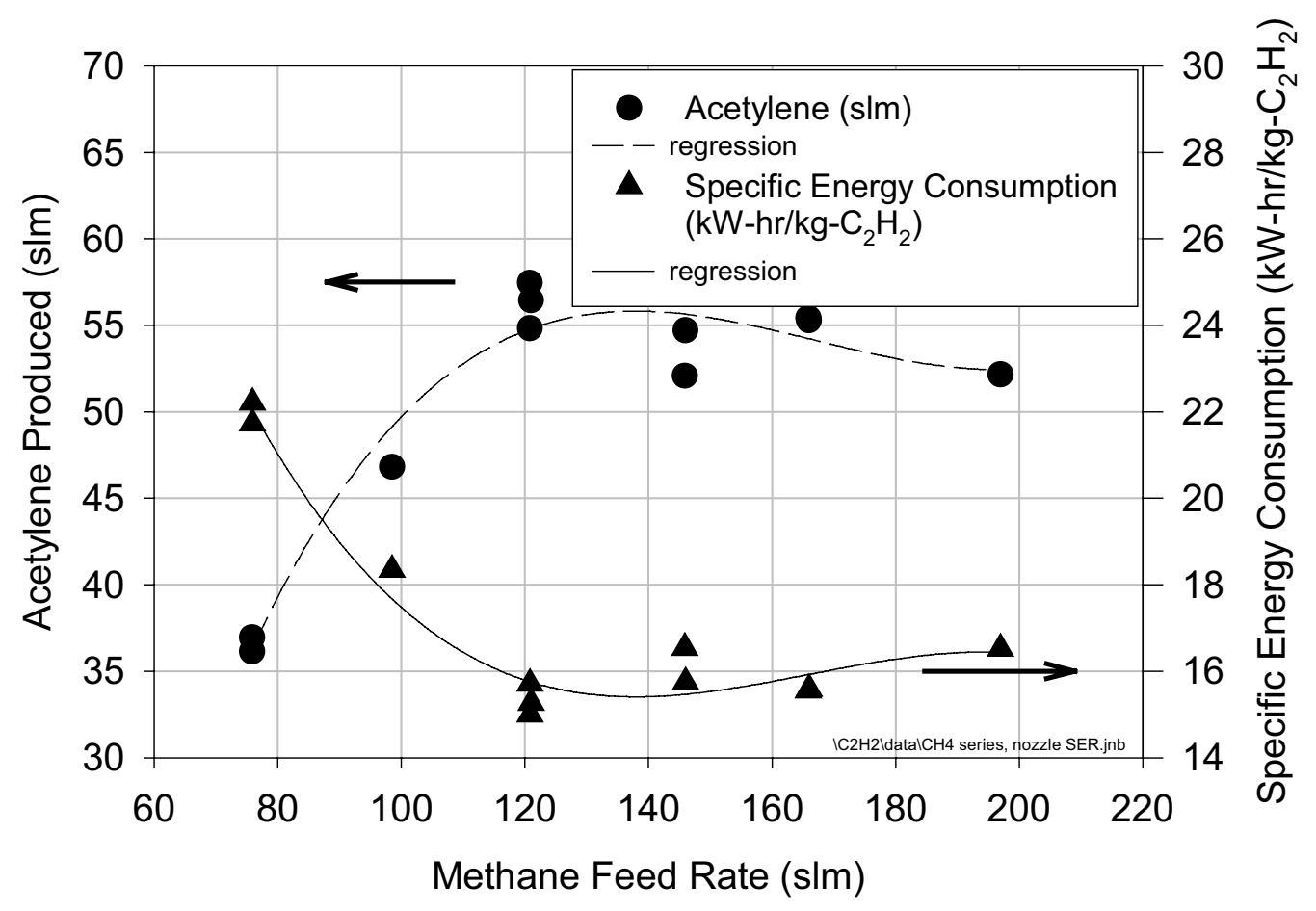

Figure 5-1. Specific energy consumption. 


\section{CONCLUSIONS}

1. Improvements in process conversion efficiency and acetylene yield over prior art are possible. The improvements are primarily accomplished by more efficient injection and mixing of reactants with plasma gases and minimization of temperature gradients and cold boundary layers in the reactor.

2. Improved mixing and thermal control also leads to increased specificity reducing the yield of hydrocarbons other than acetylene.

3. The quench rate achieved by wall heat transfer in small reactors is adequate to arrest acetylene decomposition and soot formation. Quench rates by wall heat transfer are estimated to be on the order of $0.1 \times 10^{6}{ }^{\circ} \mathrm{C} / \mathrm{s}$.

4. Formation of other hydrocarbon species, except for ethylene, is unaffected by significantly increasing the quench rate.

5. The yield of ethylene can be minimized through the addition of the aerodynamic quench process, although the effect on acetylene yield is minimal.

6. While performance enhancements by greater quench rates are marginal in small reactors, larger scale devices may benefit from quench rate enhancements.

7. While greater product selectivity for acetylene has been demonstrated, the specific energy consumption has not been improved upon. Greater specificity may reduce costs by simplifying separation product separation requirements; however, the fundamental specific energy consumption for conversion of natural gas to acetylene is on the order of $10 \mathrm{~kW}$ $\mathrm{hr} / \mathrm{kg}-\mathrm{C}_{2} \mathrm{H}_{2}$.

While methane can be efficiently converted to acetylene, the further conversion to liquid fuels must be further developed for the methane to acetylene process to play an important role in dealing with remote natural gas.

The next steps towards commercialization of the improved plasma process for the conversion of methane to acetylene are as follows:

- Demonstration of operation with methane torch gas using advanced torch technology to allow extended electrode lifetimes (see the Appendix) and elimination of argon torch gas,

- $\quad$ Establish and correct the major sources of energy inefficiencies,

- $\quad$ Engineer and build an integrated reactor system to benchmark energy efficiency and electrode lifetime expectations, and

- $\quad$ Characterize the carbon produced and determine its economic value (which will have a minor effect on the economics of the process). 


\section{REFERENCES}

Anderson, J. E. and Case, L. K., 1962, “An Analytical Approach to Plasma Torch Chemistry,” Industrial and Engineering Chemistry Process Design and Development, 1, pp. 161-165.

Detering, B. A., Donaldson, A. D., Fincke, J. R., and Kong, P. C., 1998, U.S. Patent Number 5,749,937, Fast Quench Reactor and Method.

Fields, E. K., Winzenburg, M. L., DeMarco, D. A., 1986, "Process for Preparation of Fuel Additives from Acetylene," U.S. Patent Number 4,585,897.

Fincke, J. R., Swank, W. D., and Haggard, D. C., 1993 "Transverse Injection into a Supersonic Thermal Plasma Stream," Proceedings of the $11^{\text {th }}$ International Symposium on Plasma Chemistry, ed. John Harry, Loughborough, pp. 168-171.

Frenklach, Mand, Wang, H., 1994, "Detailed Mechanism and Modeling of Soot Particle Formation," in Soot Formations in Combustion, ed. H. Bockhorn, Springer-Verlag, New York, pp. 165-192.

Gladisch, H., (1962) "How Huels Makes Acetylene by DC Arc," Hydrocarbon Processing and Petroleum Refiner, 41, pp. 159-164.

Holmes, J. M., (1969) Evaluation of DuPont Arc Process for Acetylene and Vinyl Chloride Monomer Production," ORNL-TM-2725.

Ibberson, V. J. and Sen, M., 1976, "Plasma Jet Reactor Design for Hydrocarbon Processing," Transactions Institution of Chemical Engineers, 54, pp. 265-275.

Kovener, G. S., 1983, "Use of an RF Plasma for Thermal Pyrolysis of $\mathrm{CH}_{4}$ and Heavy Oils," Proceedings of the sixth International Symposium on Plasma Chemistry, ed. M. I. Bovlos and R. J. Munz, Montreal, pp. 258-263.

Leutner, H. W. and Stokes, C. S., 1961, "Producing Acetylene in a Plasma Jet," Industrial and Engineering Chemistry, 53, pp. 341-342.

Lindstedt, R. P., 1992, “A Simple Reaction Mechanism for Soot Formations in Non-Premixed Flames, Proceedings of IVTAM Symposium, ed. R. S. L. Lee, J. H. Whitelaw, and T. S. Wang, Taipei, Springer-Verlaz. pp. 145-156.

Miller, R. and Peuckert, C., (1983) "Recent Developments the Production of Acetylene from Coal by the Hüels Arc Process," Proceedings of the sixth International Symposium on Plasma Chemistry, ed. M. I. Boulos and R. J. Munz; Montrel, pp. 207-275.

Outokumpu Research 1994, "HSC Chemistry for Windows," Version 2.03.

Peuckert, C. and Müller, R. (1985), "Acetylene from Coal by the Hüels Plasma Process, Different Operating Conditions and their Consequences for the Process," Proceedings of the Seventh International Symposium on Plasma Chemistry, ed. C. J. Timmermans; Eindhoven, pp. 274-279. 
Plotczyk, W. W., 1985, "Thermodynamic Models of Acetylene Synthesis in an Argon Plasma Jet," Proceedings of the seventh International Symposium on Plasma Chemistry, ed. C. J. Timmermans, Eindhoven, pp. 280-285.

Plotczyk, W. W., 1983, "Effect of Quenching Temperature of the Reaction on the Synthesis of Acetylene from Methane in Hydrogen Plasma Jet," Proceedings of the Sixth International Symposium on Plasma Chemistry, ed. M. I. Boulos and R. J. Mouz; Montreal, pp. 300-305.

SRI International 1998, The Chemical Economics Handbook.

Timmons, R. B., He, Yigong, and Jang, Wen-Long, 1992, “Zeolite Catalyzed Conversion of Acetylene," U.S. Patent Number 5,118,893.

Wizenburg, M. L. and DeMarco, D. A., 1991, "Process for Converting a Wet Acetylene Containing Stream to Aromatics Using a Zinc-Promoted Crystalline, Borosilicate Molecular Sieve Catalyst Composition," U.S. Patent Number 4,982,032. 


\section{Appendix A}

Evaluation of Commercially Available Plasma Systems for the Conversion of Methane to Acetylene 



\title{
Appendix A
}

\section{Evaluation of Commercially Available Plasma Systems for the Conversion of Methane to Acetylene}

\section{INTRODUCTION}

\begin{abstract}
The successful commercialization of thermal plasma conversion of natural gas to acetylene at industrial scales ultimately requires the availability of appropriate arc heater technology. The arc heater technology used in the Huels process is well developed and proven on industrial scales. It is not, however, strictly commercially available. While it is likely that the Huels technology could be licensed, the ultimate commercialization of any conversion process will depend on the availability of appropriate, industrially proven technology. With this in mind, we have surveyed both commercially available technology and developmental technologies that appear to hold some promise for large-scale application to processing of natural gas. Because the arc heater market is not large, and, in particular, the demand for processing of natural gas is currently limited, the number of possibilities is somewhat limited. There are, however, a limited number of commercially available and developmental devices that are applicable to the problem. When scaled to the $1 \mathrm{MW}$ or larger size there are only two players with proven industrial track records. These are Huels and Westinghouse Plasma Corporation. In what follows, the characteristics of thermal plasmas are briefly summarized, and their method of generation described. The results of our survey and a summary of available data is briefly discussed. Summary sheets of each technology appear in the appendix.
\end{abstract}

\section{Introduction to Thermal Plasmas}

Thermal plasmas are classified as "hot" plasmas in the American and European literature and as "low temperature" plasmas (to distinguish them from thermonuclear fusion plasmas) in the Russian literature. Depending on the gas, the pressure, and the power in the discharge, thermal plasmas generally fall in the temperature range of .5 to $2 \mathrm{eV}(6000 \mathrm{~K}-24,000 \mathrm{~K})$. Thermal plasmas are generally only partially ionized, that is enough free electrons and corresponding ions exist in sufficient numbers to make the gas electrically conductive, but the plasma may only be 10-30\% ionized. By definition thermal plasmas are in or close to local thermodynamic equilibrium (LTE) although, with the development of advanced diagnostic techniques, it has become clear that the existence of LTE in a plasma is the exception rather that the rule. Most plasmas that are classified as thermal plasmas do not meet all requirements for LTE, that is they are not in complete local thermodynamic equilibrium (CLTE). CLTE requires that the distribution of particle kinetic energies is Maxwellian, the distribution of internal energies is described by a Boltzmann distribution, and the partitioning of chemical species is described by minimization of Gibbs free energy. All distributions are characterized by a single temperature. In particular, the lower-lying energy levels of atoms may be underpopulated due to the high radiative transition probabilities of these levels, resulting in a corresponding overpopulation of the ground state. In high speed plasma flows, often characteristic of materials processing situations, deviations from both kinetic equilibrium, the electron kinetic energy distribution and heavy particle (atoms and molecules) kinetic energy distribution are both Maxwellian but are not described by the same temperature (electron temperature $\neq$ heavy particle temperature), and departures from chemical (composition) equilibrium are common. Deviations from chemical equilibrium are likely because chemical reactions cannot follow the rapid macroscopic motion of the fluid; a chemically "frozen" situation, or more commonly a " chemically retarded" situation results. Deviations from kinetic and excitation equilibrium have little importance to material processing. Deviations from chemical equilibrium are often large and can often be used to advantage. Clearly the conversion of methane to acetylene would not be nearly as successful if CLTE prevailed. 
Passing an electric current through a gas generates plasmas of the type used to process gases and solid materials. Plasma generation devices can be broadly classified as direct current (DC) or radio frequency (RF) devices. Direct current devices can be further categorized as transferred or nontransferred arc. Transferred arc devices strike an arc to the work piece and are used mostly for welding and tundish heating and melting applications. Non-transferred arc devices heat the plasma gas, which may include the reactants, the arc is contained within the torch body, and the hot gas is used externally to the torch to provide heat to the process. Direct current devices can further be categorized by the method of discharge stabilization. The main methods which are useful at the high power levels required for materials processing are vortex stabilization and magnetic stabilization.

Radio frequency devices have the advantage that they are essentially electrode-less; that is, electrical energy is coupled into the gaseous plasma medium by inductive or capacitive coupling. The "electrode" does not come into contact with the plasma gas. In capacitive coupling a high frequency ( $>30 \mathrm{MHz}$ ) electric field is responsible for maintaining the discharge. The maximum power generally available in devices of this type is less that $10 \mathrm{~kW}$. In inductively coupled devices the discharge is maintained by the time-varying magnetic field at relatively lower frequencies, generally in the range of 3-30 MHz. Power levels in the 50-100 kW range are commercially available, and a few special devices in the $500 \mathrm{~kW}-1 \mathrm{MW}$ range have been built. The major advantage of RF devices is unlimited electrode life; the disadvantages are low overall efficiency, $50 \%$ or less of the electrical energy is deposited in the gas, relatively high cost, and limited power range. For the application to the processing of natural gas, ultimately at power levels well in excess of $1 \mathrm{MW}, \mathrm{RF}$ devices are not suitable.

For DC arc gas heaters it is common to classify arc columns in terms of their methods of stabilization. There is a direct link between the method of stabilizing the arc column and the options available for the design of arc devices. For stable operation, most electric arcs require some kind of stabilizing that must be either provided externally or produced by the arc itself. Here the term stabilization refers to a particular mechanism that keeps the arc column in a given stable position, i.e., any accidental excursion of the arc from its equilibrium position causes an interaction with the stabilizing mechanism such that the arc column is forced to return to its equilibrium position. This stable position is not necessarily a stationary one; the arc may, for example, rotate or move along the cathode, anode or both with a certain velocity. Stabilization implies that the arc column can only move in a well-defined pattern controlled by the stabilization mechanism. In high intensity discharges it is advantageous and often required to keep the arc moving at high velocity. Continual movement of the arc root attachment spots reduces the local heat load, avoiding local melting and ensuing erosion. Externally controlled movement of the arc root attachment is necessary in most high current devices to prolong electrode life times.

\section{Survey of Commercial Plasma Systems}

The geometry of direct current plasma devices is generally some variation of the configuration shown in Figure A-1, courtesy of Westinghouse Plasma Corporation. The Westinghouse design utilizes a magnetic field to rotate the arc. Since an arc is an electrically conducting medium, it will interact not only with its own magnetic field but also with externally applied magnetic fields. Magnetically stabilized arcs are used extensively in the development of arc gas heaters for material processing, in circuit breakers, and in arc furnaces. The interaction of arcs with magnetic fields as applied to arc gas heaters can be roughly divided into the following categories: magnetic stabilization of arcs in cross flow and magnetically driven arcs. The first category refers to arcs exposed to strong cross flows in such a way that the arc column bends in the downstream direction if the electrode roots are fixed. In order to stabilize the arc in this situation a magnetic field is applied so that the drag force exerted on the arc by the flow is balanced by the forces due to interaction of the current and the magnetic field. Mitigation of the aerodynamic drag force is required to prevent the arc from extinguishing. The second category, 
magnetically driven arcs, is also classified as magnetically stabilized. Magnetically driven arcs are the most important category with regard to arc gas heaters. The co-axial, magnetically rotated arc has been well studied and widely applied to the efficient heating of gases to well controlled temperature levels. The Westinghouse design belongs to this category.

A variety of DC plasma devices are commercially available. The most common types are used in the thermal spray coating industry. These devices are vortex stabilized and generally operate in the power range of $25-100 \mathrm{~kW}$. They almost invariably use argon as the primary plasma gas, along with small amounts of hydrogen or helium. Electrode life is generally in the 100-200 hour range with argon mixtures and measured in minutes when operated on all hydrogen or methane. With the recent consolidation of the thermal spray industry, two companies represent $95 \%$ of the available spray devices. The two companies are Praxair and Sultzer-Metco. These devices have not been included in this survey.

There are two exceptions to this general classification. The first is the PLAZJET system developed by TAFA corp., which is now owned by Praxair. This device is capable of operating at the $250 \mathrm{~kW}$ power level, and generally runs on mixtures of nitrogen and hydrogen. The device is capable of operating on pure hydrogen. Electrode lifetimes depend strongly on the current (power) level and range from 10s of hours at high currents to 100s of hours at lower currents. PLAZJET is a high velocity, very high swirl (strong vortex) device that is applicable to but not optimized to natural gas processing. Because of the use of a tungsten cathode, using methane as the plasma gas is precluded. The carbon in the natural gas forms volatile tungsten carbides, dramatically shortening electrode lifetimes. In this same category is a unique triple cathode device developed by Northwest Mettech Corp. This device is capable of operating in the 150-200 kW range and has the unique feature that process gases can be injected coaxially on the gun centerline. Operation on pure hydrogen has been demonstrated; however, because of the use of a tungsten cathode, operation with methane as the plasma gas is not possible.

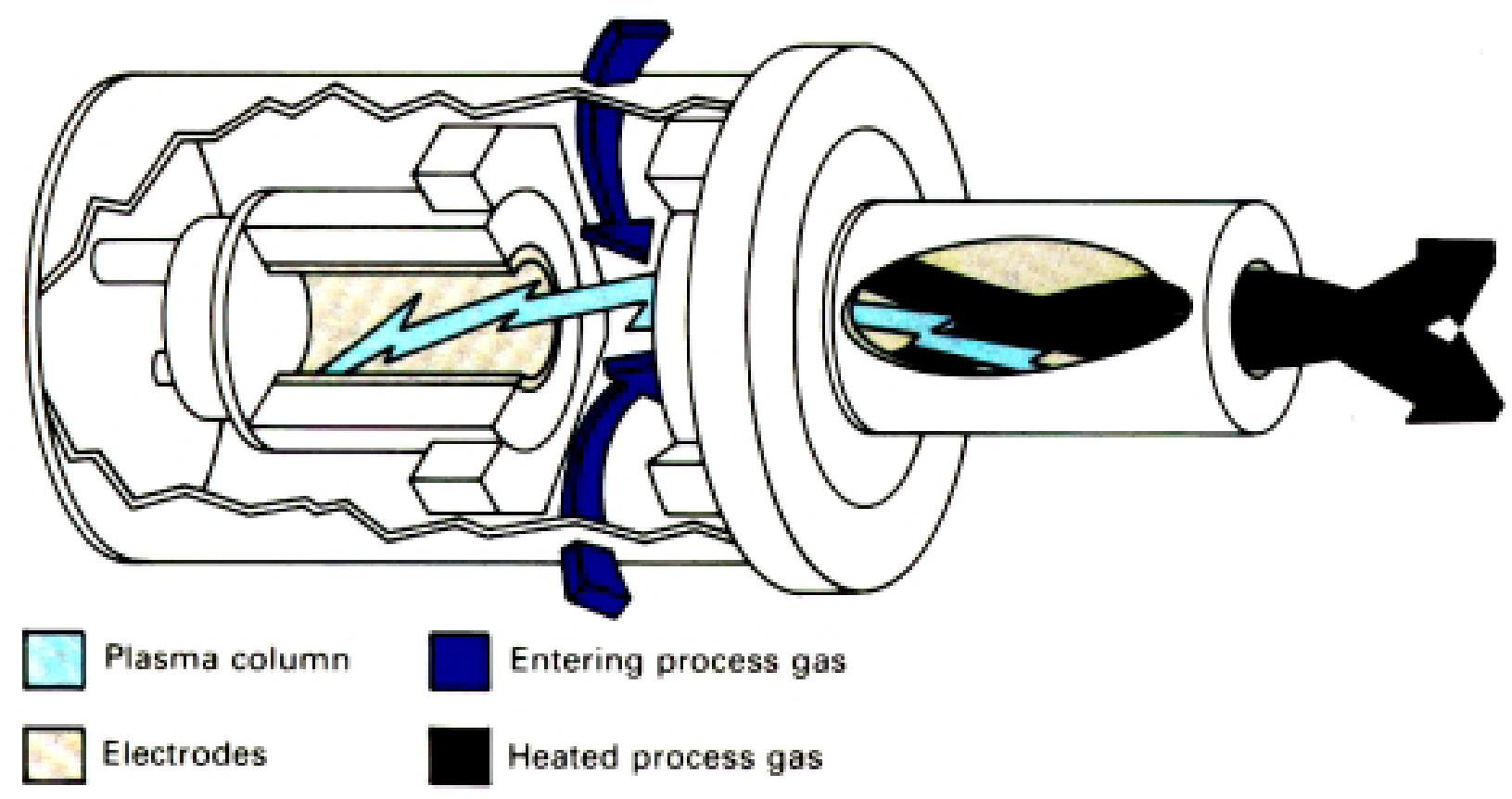

Figure A-1. Westinghouse style magnetically driven arc gas heater. 
In addition to the thermal spray devices, there are a limited number of more specialized plasma devices that were developed specifically for materials processing. These devices range from $100 \mathrm{~kW}$ to $10 \mathrm{MW}$. Because there are limited industrial applications, the demand and hence the number of suppliers is not large. These devices are summarized in Table A-1. Clearly the most readily commercially available and industrially proven are available from Westinghouse Plasma Corporation. These devices are magnetically stabilized and have successfully operated for extended periods on hydrogen and methane. While electrode life is dependent on a variety of parameters, lifetimes in the 100s of hours can reasonably be expected. Optimization could lead to longer lifetimes.

In addition to Westinghouse is the original Huels technology. While this technology is not strictly commercially available, it is probable that the technology could be licensed directly from Huels. The Huels device is vortex stabilized and can be sized to the 8-10 MW range. Anode lifetimes of 250 hours are reported. The other major player is Plasma Technology Corporation. Plasma Technology Corporation can provide 100-250 kW devices which are capable of operating on hydrogen and/or methane with claimed electrode lifetimes in the 150-300 hour range at $250 \mathrm{~kW}$.

There are three additional players in this arena, with limited track records. The first is a unique triple cathode, three phase AC device developed in France by Fulcheri. This device uses carbon cathodes and runs on conditioned three-phase AC power direct from the power line. Operation on methane has been demonstrated and the device has been reportedly used at the pilot plant scale for the conversion of natural gas to hydrogen and carbon black. Electrode lifetimes and other details are not available in the open literature. However, direct contact with Fulcheri has indicated that this information can be obtained under cover of a non-disclosure agreement. The second player is Phoenix Solutions Co. This company supplies DC torch systems in the $100 \mathrm{~kW}$ to $1.5 \mathrm{MW}$ scale primarily for metals and solid waste processing. As claimed by the manufacturer the technology can be modified for gas processing; however, few details and limited demonstration data is currently available. The third is Plasma Quench Technology, Inc. in Idaho Falls, ID. This company is an INEEL spin-off that has developed proprietary arc heater technology for processing $\mathrm{TiCl}_{4}$. Because of the proprietary nature of the device (a combined torch/reactor), little information is publicly available. The developer conducts operation with corrosive materials including chlorine and oxygen and indicates that the device should be capable of processing natural gas or methane.

\section{Summary and Conclusions}

In order to achieve energy efficient operation it is necessary that at fraction of the total flow rate of natural gas pass through the arc region itself. Even when natural gas is used as some or even all of the plasma gases there will still be downstream injection of reactants to attain the target temperature in the reactor. Operation with carbon containing species in the discharge region poses three problems:

(1) materials used must be compatible with the surrounding atmosphere; materials which form volatile carbides, for instance, must be avoided; (2) the arc becomes highly constricted increasing the local heat load on the anode and must be forced to move by either swirl or magnetic fields; and (3) solid carbon or soot can be produced which deposits on flow channel walls. Suitable anode and cathode materials that have the required characteristics for heat transfer and thermionic emission exist and their performance has been demonstrated. Both swirl and magnetic arc rotation are reasonably well understood and have been successfully used. Control of soot formation is less well understood; however, data suggest that the addition of hydrogen in the plasma gas tends to suppress soot formation.

The Westinghouse Plasma Corporation systems currently appear to have a significant edge over other available devices. This is due to the corporate commitment the original Westinghouse Electric Corporation made for many years in developing plasma technology. This commitment resulted in the development of devices ranging in power from $50 \mathrm{~kW}-3000 \mathrm{~kW}$. These devices have been put into 
industrial operation and have a proven track record of industrial performance. The original technology base is retained and is currently owned by Westinghouse Plasma Corporation. Traditionally the Westinghouse devices have been used as arc heaters for melting applications, and operation on methane rich gases has not been demonstrated for essentially continuous operation for long time periods. Based on other information, however, it is likely that the technology will survive operation on methane with lifetimes that are comparable to conventional arc heating applications.

Further progress toward commercialization of plasma conversion of methane to acetylene will require evaluation of the process with more advanced plasma processing equipment such as that available from Westinghouse. This evaluation should include determination of the value of aerodynamic quench for rapid cooling at reactor and production scales beyond that used in the current study. 


\title{
Table A-1 \\ Methane/Hydrogen Plasma Torch Technology Survey
}

\author{
Company Listing \\ Centre d'Energétique Etablissement de Sophia-Antipolis \\ Huels-AG \\ Idaho National Engineering and Environmental Laboratory (INEEL) \\ Phoenix Solutions Co. \\ Plasma Quench Technologies, Inc. \\ Plasma Technology Corporation \\ TAFA Corp. \\ Westinghouse Plasma Corporation
}




\section{Centre d'Energétique Etablissement de Sophia-Antipolis}

$\begin{array}{ll}\text { Contact: } & \text { Laurent Fulcheri } \\ \text { Address: } & \text { Ecole des Mines de Paris } \\ & \text { Centre d'Energétique } \\ & \text { BP207 } \\ & 06904 \text { Sophia-Antipolis Cedex } \\ & \text { Paris, France } \\ & \text { Tél : +33 } 0493957406 \\ & \text { Fax }:+330493957535 \\ & \text { Gilles Flamant } \\ & \text { IMP-CNRS } \\ & \text { B.P. 5-66 } \\ & \text { 120 Font-Romeu Cedex } \\ & \text { Paris, France } \\ & \text { Tél : +33 05 68 30 77 58 } \\ & \text { Fax : + 33 05 68 30 29 40 } \\ & \text { e-mail: fulcheri@cenerg.cma.fr } \\ & \text { Web Site: http://www-cenerg.cma.fr/eng }\end{array}$

Plasma Torch Device Type: $\quad$ AC Three Electrode, Non-transferred Arc Plasma

Electrode Type: Consumable Carbon Electrode

Electrode Life-Time: Consumable carbon with automatic electrode feed system

Plasma Torch Model: $\quad$ This research center does not sell plasma equipment

Pilot Scale Research Plasma Device

200-400 VAC at 200-400 Amps

Facility requirements: $\quad$ Not applicable

Cost: $\quad \$ 50 \mathrm{~K}-75 \mathrm{~K}$ to construct a $169 \mathrm{~kW}$ pilot scale device in house

Literature:

Fulcheri, L., Schwob, Y., "From methane to hydrogen, carbon black and water,

International Journal of Hydrogen Energy," vol 20, No. 3, pp. 197-202, 1995.

Fulcheri, L., Variot, B., Flamant, G., Schwob, Y., Kassabji, F., Vallbona, G., Saint-Just, J., Fischer, F., "A 3-Phase A. C. Plasma Process for Carbon Black Production from Methane, Thermal Plasma Processes," 19-21 Sept. 94, Aachem Germany, VDI BERICHTE NR 1166, pp 525-532, 1995.

Fulcheri, L., Schwob, Y., "Comparison between two carbon nanostructures: furnace and acetylene blacks," NANOS 94, Int. Workshop on nanostructured materials," 6-8 January 1994, Odeillo France, High Temp. Chem. Processes 3, 575-583, 1994. 
Fulcheri, L., Flamant, G., Variot, B., Ravary, B., Badie, J. M., "Characterization of a 3-phase AC plasma reactor for carbon black synthesis from natural gas," ISPC 12, August 21-25 1995, Minneapolis, Minnesota USA, vol III, pp 1159-1164.

Fulcheri, L., "New 3-Phase AC plasma pilot for carbon black production from Hydrocarbons.” Intertech Conferences, Carbon Black World 96, 4-6 March 1996, Nice-France.

Fulcheri, L., Schwob, Y., Flamant, G., "Comparison between new carbon nanostructures produced by plasma cracking with industrial carbon black grades," NANOS 96, Odeillo. to be published

\section{Discussion:}

\section{Laurent Fulcheri, Research Area}

Utilization of thermal plasmas can, in some instances, provide original solutions to energy and environmental problems resulting from modern industrial activities. They can, for example, contribute to improving the energy efficiency of existing processes and the reduction of solid and gaseous waste. Research in this field involves the development of new, clean, economic procedures. Two applications are under way. The first concerns the development of a process for hydrocarbon cracking for the production of carbon and hydrogen black. The second refers to the production of new carbon nanostructures, particularly fullerenes.

\section{FRENCH THREE-ELECTRODE PLASMA REACTOR}

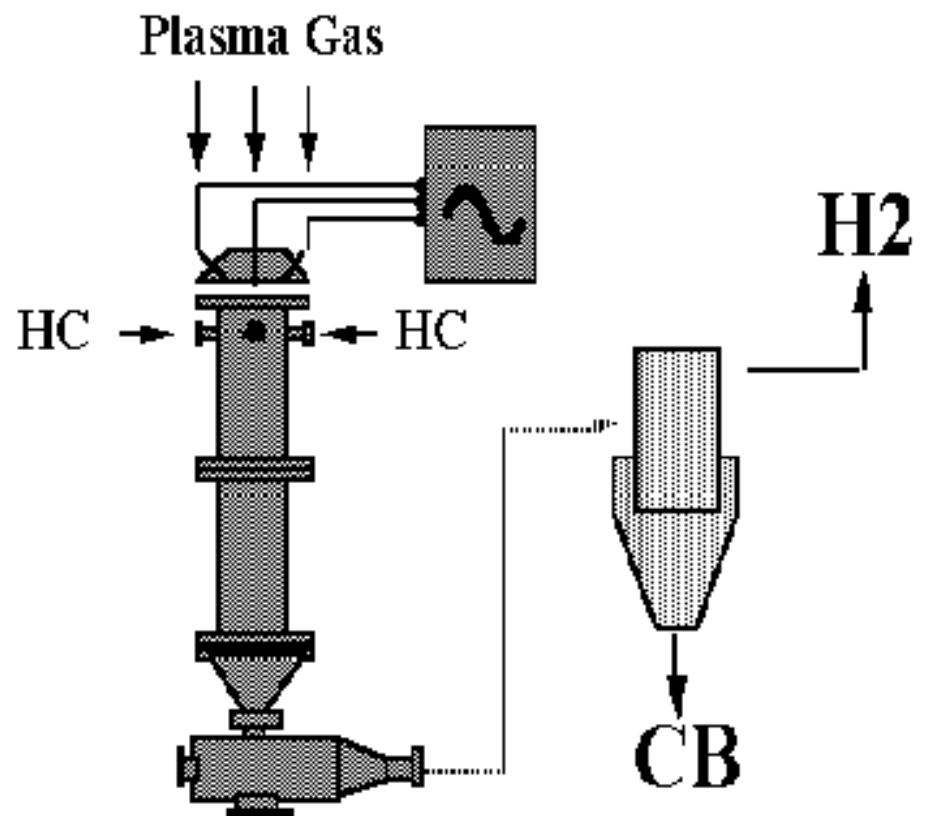




\section{Huels-AG}

Contact: None

Address: Huels-AG

Postfach 1320

4370 Marl, Germany

Tel: +492365490

Fax: +492365 492000

e-mail: Not Available

Web Site: www-x500-2.uni-giessen.de:8890/Lo\%3dHuelsAG,20\%c\%3dDE

Plasma Torch Device Type: $\quad$ DC Transferred Arc

Electrode Life Time: $\quad$ Carbon Steel Cathode-1000 hours

Carbon Steel Anode-250 hours

Plasma Torch Models offered: 150 kW Model \& MW Model

Capable of operation on light hydrocarbon gases \& hydrogen. $10 \mathrm{MW}$ model currently operated on $\mathrm{C}_{4}$ hydrocarbon gases.

Literature:

"The use of Plasma Processes for Chemical Reactions \& Metals Smelting at Chemishe Werke Huels," ARC Plasma Processes: A Maturing Technology in Industry, UIE ARC Plasma Review 1988, International Union for Electro Heat, pp. 113-120, 1988.

Discussion:

The Arc Process reactor is represented in the figure below. The plasma generating gas $\left(\mathrm{C}_{1}-\mathrm{C}_{4}\right)$ is tangentially injected between the electrodes with the help of an injection device (1), so that a gas vortex forms in the plasma furnace. The arc is initiated between the bell shaped cathode (3) and the tubular anode (4). The arc mainly burns in the dead zone of the vortex. The roots of the arc on the electrodes are forced into a rapid rotation by the vortex flow, so that the arc only burns for a fraction of a millisecond on any given point, which increases the lifetime of the electrodes.

The arc length is about 1-1.2 $\mathrm{m}$ and roots at approximately $50 \mathrm{~cm}$ inside the anode. At $20 \mathrm{~cm}$ below the arc root in the anode, hydrocarbons are injected by 3 inlets set at $120^{\circ}(6)$; they cool the plasma gas, but are also heated, cracked and partially transformed into acetylene and ethylene. At the outlet of the tubular anode, the product gases are quenched to $450-500 \mathrm{~K}$ by water injection (7). The reactor is powered by $\mathrm{DC}$ at $7000 \mathrm{~V}$ and $1200 \mathrm{~A}$. The lifetime of the carbon steel electrodes is 100 hours for the anode and 250 hours for the cathode. 


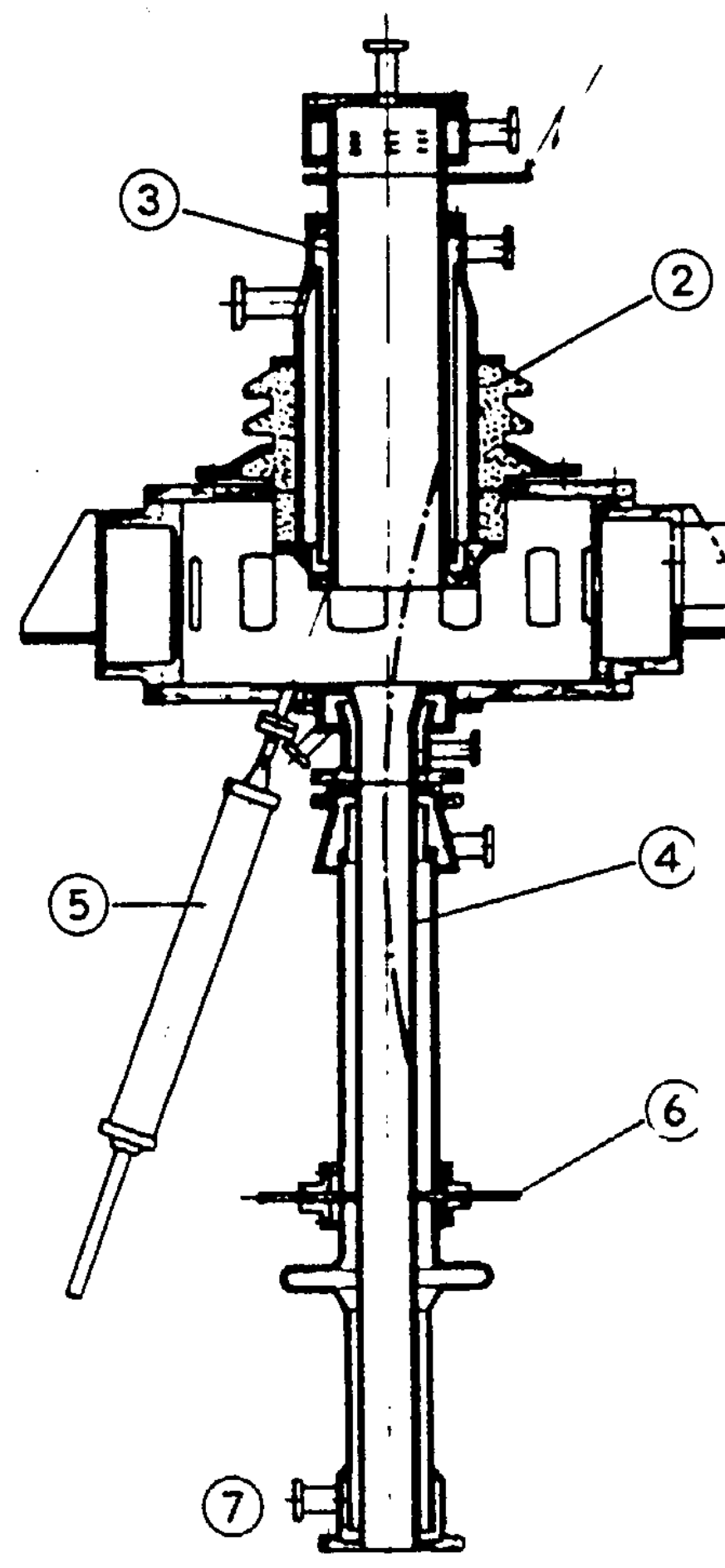

1. Gas inlet

2. Insulator

3. Cathode

4. Flame tube Reactor-Anode

5. Ignition device

6. Mixer-prequench

7. Quench water 


\section{Idaho National Energy and Environmental Laboratory (INEEL)}

Contact: J. R. Fincke

Address: $\quad$ INEEL

P.O. Box 1625

Idaho Falls, ID 83402-2110

Tel: 208-526-2031

Fax: 208-526-5327

e-mail: jfl@inel.gov

Plasma Torch Device Type: $\quad$ Non-transferred Arc Torch

Electrode Life Time: $\quad 50-100 \mathrm{hrs} \mathrm{Ar} / \mathrm{H}_{2}$ mixtures

Has not been operated on methane.

Plasma Torch Models offered: $\quad$ INEEL modification of $160 \mathrm{~kW}$ TAFA model 151. Model 151 has been superseded by the PLAZJET® system and is not longer commercially available.

Facility requirements:

$$
\begin{aligned}
& \text { AC Power input: } \quad 460 \mathrm{VAC}, 180 \mathrm{Amps} \\
& \text { Plant Water: } \quad 7 \mathrm{gpm} \\
& \text { Input gases: } \quad \text { Ar 100-200 1/min hydrogen 100-200 1/min } \\
& \text { Space requirements: Power Supplies - 3ea. }-1 \text { meter cube } \\
& \text { Control Cabinet }-1 \text { ea. }-1 \text { meter cube }
\end{aligned}
$$

Cost: $\quad$ Not commercially available

Literature:

$$
\text { U.S. Patent 5,749,937, Fast Quench Reactor and Method }
$$

Discussion:

INEEL does not provide commercial plasma equipment but does provide research and process development services. 


\section{Phoenix Solutions Co.}

Contact: $\quad$ Douglas L. Frame, V.P. Sales

Address: $\quad$ Phoenix Solutions Co. 5900 Olson Memorial Hwy. Minneapolis, MN 55422 USA

Tel: $\quad$ (612) $544-2721$

Fax: (612) 546-5617

e-mail: $\quad$ phoenixsolutions@compuserve.com

Web Site: www.phoenixsolutionsco.com

Plasma Torch Device Type: $\quad$ DC Transferred Arc Plasma, Hollow Cathode, Reverse Polarity

Electrode Life Time: $\quad$ 100-800 hours depending on plasma gas used

Plasma Torch Models offered: $300 \mathrm{~kW}, 500 \mathrm{~kW}, 1.0 \mathrm{MW}, 1.5 \mathrm{MW}$ Model DC

Plasma Gases: $\quad$ Argon, nitrogen, carbon monoxide, methane, natural gas

Facility requirements: $\quad$ Not available

Cost: $\quad \$ 250 \mathrm{~K}$

Literature:

U.S. Patent No. $5,451,740$

Discussion:

Phoenix provides plasma arc torch systems for metals and waste processing, $100 \mathrm{~kW}$ to $1.5 \mathrm{MW}$. They operate in transferred or non-transferred arc modes, for industrial process and other applications. 


\section{Plasma Quench Technologies, Inc.}

\begin{tabular}{|c|c|c|}
\hline Contact: & \multicolumn{2}{|c|}{ Alan Donaldson } \\
\hline \multirow[t]{5}{*}{ Address: } & \multicolumn{2}{|c|}{$\begin{array}{l}\text { Plasma Quench Technologies, Inc. } \\
101 \text { Technology Drive } \\
\text { Idaho Falls, ID 83401-1584 }\end{array}$} \\
\hline & Tel: & $208-522-9909$ \\
\hline & Fax: & $208-523-6885$ \\
\hline & e-mail: & pqti@aol.com \\
\hline & Web Site: & www.pqti.com \\
\hline
\end{tabular}

Plasma Torch Device Type: $\quad$ DC, Hybrid Transferred/Non-Transferred. The arc is in the reactor; the arc traverses the reactor so it is more similar to Transferred.

Electrode Life Time: Depends on the environment. No less that a dozen hours. Up to 100s of hours depending on application. The two electrodes are very inexpensive and can be replaced rapidly.

Plasma Torch Models offered: Not applicable

Has $500 \mathrm{~kW}$ and 1.2 MW models in-house. See discussion below.

Facility requirements: $\quad$ Not applicable

Literature: $\quad$ Not available

Discussion:

The Plasma Quench Technologies, Inc. technology is unique in that the arc is in the reactor. Typically, the reactant species makes up the arc; a separate plasma gas is not used. This technology offers very high heat transfer rates and very high efficiencies. PQTI provides custom processing and will provide custom design services for combined reactor/torch combinations. PQTI has specialized in reduction of metals; e.g., the production of titanium powder from titanium tetrachloride. Hydrogen has been used but not at high levels. Methane has not been used in the past but will be in the near future. 


\section{Plasma Technology Corporation}

Contact: $\quad$ Dr. S. L. "Bud" Comacho

Address: $\quad$ Plasma Technology Corporation

8913 O'NEAL Road

Raleigh, NC 27613

PH: (919) 845-8987

e-mail: Not Available

Web Site: Not Available

Plasma Torch Device Type: $\quad$ DC Non-transferred Arc Plasma, Hollow Cathode Design, Reverse Polarity

Electrode Life: 20-300 hours

Plasma Torch Models offered:

$100 \mathrm{~kW}$ Plasma Torch, 20-50 hours electrode life

$250 \mathrm{~kW}$ Plasma Torch, 150-300 hours electrode life

Facility requirements

$100 \mathrm{~kW}$ System, $100 \mathrm{~kW}$ DC reverse polarity power supply, $460 \mathrm{VAC}, 250 \mathrm{Amp}$ 20 gpm plant cooling water input

250 kW System, 300 kW reverse polarity DC Power Supply, 460 VAC, 750 Amp

40 gpm plant cooling water input

Literature:

U.S. Patent No. 5,451,740 


\section{TAFA Corp.}

Contact: $\quad$ Vladamir Belashchenko

Address: $\quad$ TAFA Corp/Praxair

146 Peinbroke Road

Concord, NH 03301

Tel: $603-223-2188$

Fax: 603-224-8039

e-mail: vlad@tafa.com

Web Site: www.tafa.com

Plasma Torch Device Type: Non-transferred Arc Torch

Electrode Life Time: $\quad 50-100 \mathrm{hrs} \mathrm{N}_{2} / \mathrm{H}_{2}$ mixtures

50-100 hours on hydrogen,

Has not been operated on methane.

Plasma Torch Models offered: One Model $250 \mathrm{KW}$

PLAZJET

Facility requirements:
AC Power input:
460 VAC, 180 Amps
Plant Water:
$7 \mathrm{gpm}$
Input gases:
Nitrogen 600 1/min hydrogen 600 1/min
Space requirements:
Power Supplies - 2ea. - 1 meter cube
Control Cabinet-1 ea.-I meter cube

Cost:

\$250K US 


\title{
Westinghouse Plasma Corporation
}

\author{
Contact: $\quad$ Dr. Shyam Dighe, President \& CTO \\ Mr. Dan Lazzara, COO \\ Address: Westinghouse Plasma Corporation \\ Plasma Center \\ Waltz Mill Site \\ P.O. Box 410 \\ Madison, PA 15663
}

Tel: $724-722-5872$

Fax: 724-722-5205

e-mail: http://www.westinghouse-plasma.com/comemail.htm

Web Site: http://www.westinghouse-plasma.com/typplsys.

Plasma Torch Device Type: Non-Transferred, DC

Electrode Life Time: $\quad$ 100s of hours

Plasma Torch Models offered: DC Non-transferred Arc Plasma Torches

MARC-3-300 kW system- $\$ 300 \mathrm{~K}$

MARC-11-2500 kW system-\$1,000K

Westinghouse has operated the MARC- $=11$ plasma torch in AC Mode on $0.2 \mathrm{lb} . / \mathrm{sec}$ Methane at $1000 \mathrm{~kW}$.

Facility requirements: $\quad$ Not available

Literature:

U.S. Patent No. 3,697,612, October 10, 1972 Production of Acetylene with an Arc Heater," Daniel Maniero, et. al

Discussion:

As shown in figure 1 in this report, the plasma torch consists of a closely spaced pair of tubular watercooled electrodes within which an electric arc discharge is magnetically rotated at extremely high speeds. During operation, a process gas is injected into the heater through a space (approximately $1 \mathrm{~mm}$ ) between the electrodes.

Sparkover between the electrodes initiates the arc discharge when the power supply is energized. The arc is immediately blown to the interior of the electrode by the incoming process gas. The arc current interacts with a magnetic field established by solenoid field coils located around both the upstream and downstream electrodes to rotate the arc at approximately 1000 revolutions/second. The combination of high arc rotation speeds and high gas flow rates provides an excellent heat transfer between the electric arc and the incoming process gas, and also maximizes electrode life. It is this excellent high arc/gas interaction that produces the superheated process gas and leads to the thermal efficiencies obtained for this type of torch. 
Appendix B

Representative Data Tables 



\section{Appendix B \\ Representative Data Tables \\ INTRODUCTION}

Voluminous data is produced in each experimental run. All instrumentation except for the gas chromatograph is directly interfaced to a data acquisition system for continuous recording of system parameters during a test run. The most significant run parameters and test data for each run are summarized on a spreadsheet. Table B-1 is a key describing the various parameters that are recorded on the spreadsheets. This key should be used in combination with the map shown in Table B-2 which shows where the various measurements are located in the data tables. Test data for a ten typical runs are provided in Tables B-3 through B-12. Each spreadsheet contains two sets of output data-one based on the downstream turbine meter and the other based on argon input and gas chromatography data as described in the main body of the report. While the two sets of data are sometimes in excellent agreement, output measurements from the turbine meter are often low due to sticking of the meter as described earlier. The shaded columns allow ready comparison of the input and output of total mass and carbon. Columns for product yields (on a carbon basis) are also shaded. 


\section{Table B-1. Key for Appendix B Data Tables}

1. Test designation and summary of flow rates (in standard liters per minute, slm), power, measured torch thermal efficiency, nozzle geometry, and reactor and exit pressures.

2. Row designator.

3. Yield of acetylene and hydrogen from methane feedstock and measured conversion efficiency. The acetylene yield is the percent of the carbon in the methane feedstock that ends up in acetylene and the hydrogen yield is the percent of the hydrogen in the methane feedstock that ends up as elemental hydrogen. Qt denotes measurements based on the downstream turbine flow meter.

4. Yield of acetylene and hydrogen from methane feedstock and measured conversion efficiency. Q Ar std denotes measurements based on input flow rate of argon and gas chromatography data.

5. Volumetric flow rate of acetylene and hydrogen generated from methane feedstock. Qt denotes measurements based on the downstream turbine flow meter.

6. Volumetric flow rate of acetylene and hydrogen generated from methane feedstock. Q Ar std denotes measurements based on input flow rate of argon and gas chromatography data.

7. Specific Energy Requirement in units of kW-hr/kg product. Qt denotes measurements based on the downstream turbine flow meter.

8. Specific Energy Requirement in units of $\mathrm{kW}-\mathrm{hr} / \mathrm{kg}$ product. Q Ar std denotes measurements based on input flow rate of argon and gas chromatography data.

9. Same as 7 in units of $\mathrm{kW}-\mathrm{hr} / \mathrm{Mscf}$.

10. Same as 8 in units of $\mathrm{kW}-\mathrm{hr} / \mathrm{Mscf}$.

11. Relative yield; yield numbers have been normalized for conversion efficiency.

12. Species measured by gas chromatography.

13. Molecular weight of species.

14. Number of carbon atoms.

15. Number of hydrogen atoms.

16. Concentration in mole percent measured by gas chromatography.

17. Volumetric input flow rates in standard liters per minute.

18. Mass flow rates in grams per minute corresponding to input volumetric flow rates.

19. Volumetric flow rate measured by downstream turbine meter in standard liters per minute.

20. Corresponding total mass flow rates in grams per minute. 
21. Input hydrogen mass flow rates in grams per minute.

22. Measured hydrogen product stream mass flow in grams per minute using downstream turbine meter and gas chromatography.

23. Input carbon mass flow rates in grams per minute.

24. Measured carbon product stream mass flow in grams per minute using downstream turbine meter and gas chromatography.

25. Carbon basis yield using downstream turbine meter and gas chromatography.

26. Estimated product stream volumetric flow rate in standard liters per minute using input flow rate of argon and gas chromatography data.

27. Measured product stream total mass flow rate in grams per minute using input flow rate of argon and gas chromatography data.

28. Measured product stream hydrogen flow rate in grams per minute using input flow rate of argon and gas chromatography data.

29. Measured product stream carbon mass flow rate in grams per minute using input flow rate of argon and gas chromatography data.

30. Carbon basis yield using input flow rate of argon and gas chromatography data.

31. Column totals in grams per minute.

32. Percentage difference between input values and measured product stream values. A negative value indicates the output was greater that the input.

33. Estimate of the amount of soot produced based on mass balance measurements. A negative value indicates the carbon output in the products was greater than the input. 